\title{
A Moisture Budget Analysis of the Protracted Heat Wave in the Southern Plains during the Summer of 1980
}

\author{
WINSTON HAO AND LANCE F. BOSART \\ Department of Atmospheric Science, State University of New York at Albany, Albany, NY 12222
}

(Manuscript received 14 April 1987, in final form 26 June 1987)

\begin{abstract}
Extreme heat and drought plagued much of the south central United States during the summer of 1980 in response to a quasi-stationary persistent anticyclone aloft. Numerous weather reporting stations in the Southern Plains experienced a dewpoint temperature decrease of about $1^{\circ} \mathrm{C}$ per week from late June to late July in response to the intense heat.

In this paper evaporation is computed as a residual from the large-scale moisture budget based upon the observed twice daily radiosonde data. From 1 June to 31 August 1980 the average daily evaporation amounted to $8 \mathrm{~mm}$ for a $4 \times 10^{5} \mathrm{~km}^{2}$ region centered over Oklahoma. On individual days the evaporation was as high as $10-15 \mathrm{~mm}$.

Strong diurnal variations were computed in the water vapor flux, vertical velocity and horizontal divergence fields. These variations, when superimposed over persistent large-scale subsidence, yielded enhanced subsidence, low-level divergence and anticyclonic vorticity production by day and weakened subsidence by night. The maximum diurnal variation in vertical motion was located near $700 \mathrm{mb}$ and averaged $2-3 \mathrm{~cm} \mathrm{~s}^{-1}$. Comparison with 1979 results, a slightly cooler and wetter than normal summer, showed that the diurnal signal was quite amplified in 1980. The more normal Great Plains pattern of nighttime convergence, weak surface cyclonic vorticity and ascent was seldom seen in 1980 and then only in conjunction with the passage of rare synopticscale disturbances.

The vertical profiles of equivalent potential temperature across the Southern Plains were comparable in 1979 and 1980, ranging from $\theta_{e} \sim 340-345 \mathrm{~K}$ at the surface to $\sim 330 \mathrm{~K}$ at $600 \mathrm{mb}$. In contrast, the surface saturation equivalent potential temperature was much warmer in 1980 than $1979(\sim 385 \mathrm{~K}$ vs $360 \mathrm{~K})$. Consequently, the level of free convection was much higher in $1980(\sim 600 \mathrm{mb})$ and organized convective systems could not be triggered in the absence of synoptic-scale forcing. Evaporation in the absence of precipitation resulted in the presumed depletion of soil moisture and even higher surface temperatures as almost all of the available solar insolation went into sensible heat. Daytime subsidence reinforced the heating and drying of the atmosphere in a positive feedback process that likely contributed to the maintenance of the hot, dry conditions under the favorable synoptic-scale anticyclone regime.
\end{abstract}

\section{Introduction}

The summer of 1980 was noteworthy for a protracted heat wave and drought in much of the Southern and Central Plains of the United States. Details on the circulation regimes and weather extremes can be found in Dickson (1980), Livezey (1980), and Wagner (1980). According to Karl and Quayle (1981) the summer of 1980 represented an extreme anomaly in terms of prolonged heat and drought across the southern United States in comparison to the previous 20 years. They indicated that nearly 1300 deaths could be attributed to the intense heat. Economic losses were estimated at $\$ 16$ billion (1980 dollars), mainly due to crop and livestock losses, increased energy demand for cooling, and extensive highway damage.

In late May of 1980 a strong subtropical anticyclone became established in the mid- and upper troposphere over the Southern Great Plains. The anticyclone, once established, remained in place for most of the rest of the summer with only a few interruptions by synoptic- scale cyclones. Following a relatively wet spring in much of the region, prolonged subsidence, clear skies and high insolation resulted in the depletion of soil moisture and produced unrelenting heat. Daily maximum temperatures near or in excess of $40^{\circ} \mathrm{C}$ were common across much of the Southern Plains for weeks. Kalkstein and Valimont (1986), in a study of summer discomfort over a 10 -year period, found that eight and five of the ten warmest days (in terms of apparent temperature) at Mobile, Alabama (MOB) and Tulsa, Oklahoma (TUL), respectively, occurred during the summer of 1980.

In the core of the heat wave area of Oklahoma, northern Texas, southern Kansas and western Arkansas (area 1 in Fig. 1) the July mean temperature averaged $3.1^{\circ} \mathrm{C}$ above normal while precipitation was $<25 \%$ of normal (Table 1). Anomalies of like sign prevailed in June and August as well. These numbers stand out in sharp contrast to the relatively cool and wet summer of 1979 in the same region. 


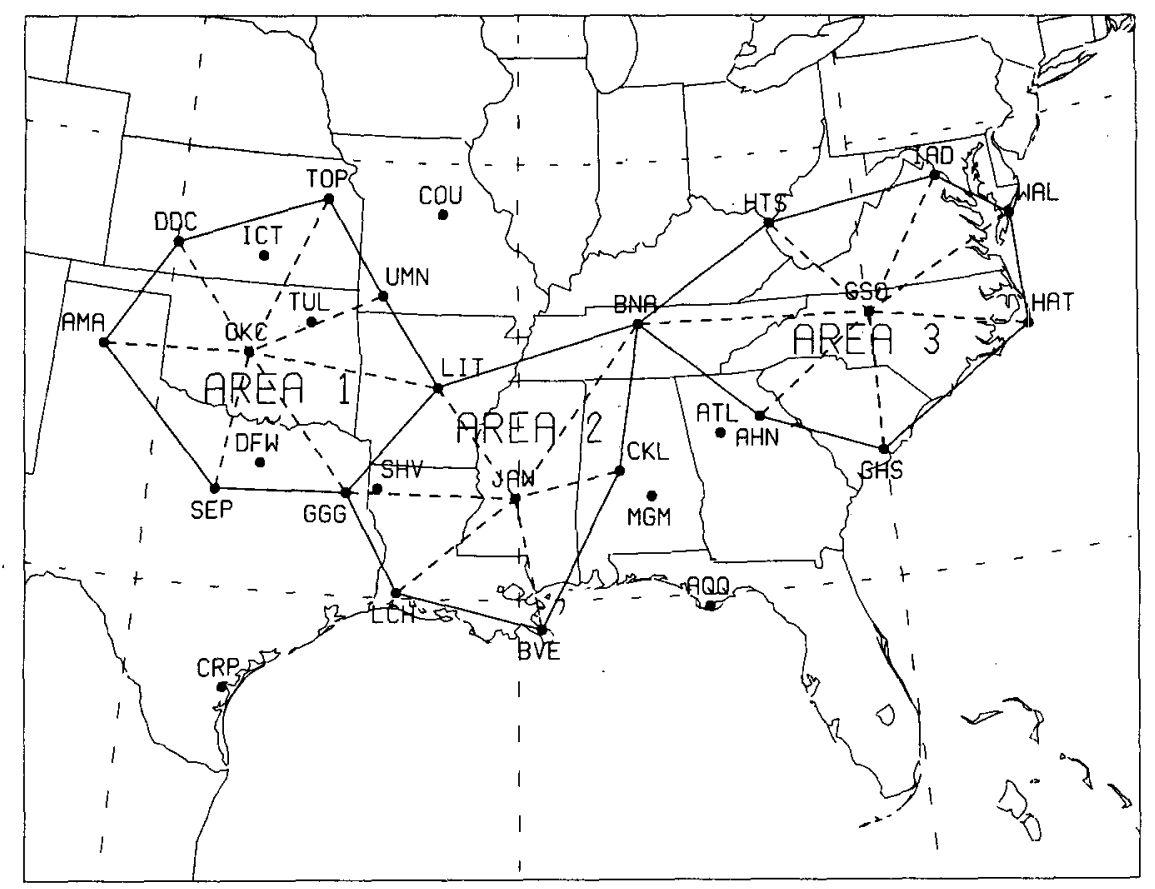

Fig. 1. Three-letter station identifiers for locations mentioned in text and moisture budget computational areas.

Our interest in this case was prompted by real-time observations by the senior author of dewpoint temperature decreases by roughly $1^{\circ} \mathrm{C}$ per week as the heat intensified across much of the region.

Periodic episodes of prolonged and intense drought are a recurring global phenomenon that have attracted the attention of numerous researchers. Namias (1982, 1983) found that strong subtropical ridges located in the eastern Pacific, the Central Plains and the central Atlantic during the summer of 1980 replicated circulation patterns documented during other major summer droughts in the United States. He hypothesized that an extensive region of below normal sea surface temperatures in the North Pacific ocean basin during the previous winter and spring resulted in a coupled atmosphere-ocean feedback system that contributed to the intensity and persistence of the aforementioned

TABLE 1. Monthly values of temperature and precipitation and anomalies (parentheses) for 1979 and 1980 in area 1 of Fig. 1.

\begin{tabular}{|c|c|c|c|}
\hline Year & June & July & August \\
\hline \multicolumn{4}{|c|}{ Temperature $\left({ }^{\circ} \mathrm{C}\right)$} \\
\hline $\begin{array}{l}1979 \\
1980\end{array}$ & $\begin{array}{l}23.9(-1.0) \\
26.5(1.6)\end{array}$ & $\begin{array}{l}26.7(-0.6) \\
30.4(3.1)\end{array}$ & $\begin{array}{l}25.7(-1.2) \\
29.1(2.2)\end{array}$ \\
\hline \multicolumn{4}{|c|}{ Precipitation (cm) } \\
\hline $\begin{array}{l}1979 \\
1980\end{array}$ & $\begin{array}{c}11.0(0.7) \\
6.1(-4.2)\end{array}$ & $\begin{array}{c}12.6(4.2) \\
2.0(-6.4)\end{array}$ & $\begin{array}{l}7.3(-0.2) \\
4.2(-3.3)\end{array}$ \\
\hline
\end{tabular}

three cell pattern. Other investigators have invoked high dust concentrations (Twomey and Squires, 1959), soil moisture deficiencies (Mintz and Shukla, 1982; Rowntree and Bolton, 1983; Gutman, 1984; Yeh et al., 1984) and dynamical processes based upon surface heating (Charney, 1975, 1976; Charney et al., 1975, 1976, 1977) to explain persistent drought episodes.

The purpose of this paper is threefold. First, a synopsis of the daily temperature and dewpoint temperature readings is compared against climatology for selected stations during the summer of 1980 . Second, the operational domestic radiosonde network is used to compute a twice daily moisture budget from which the daily evaporation is derived as a residual and compared to other independent estimates of evaporation. Third, the moisture flux divergence, kinematic relative vorticity and vertical velocity are stratified by 0000 and 1200 UTC to deduce the diurnal signal. This information is used to compare the diurnal and synopticscale circulation variations for selective regions during the dry and wet summers of 1980 and 1979 respectively.

\section{Data and analysis methods \\ a. Data}

Twice daily upper air data was obtained from the National Center for Atmospheric Research (NCAR) for a total of 39 radiosonde stations (appendix A) cov- 
ering most of the central and eastern United States for the period 1 June through 31 August of 1979 and 1980. Mandatory and significant level temperature, moisture, and wind data were included in every sounding from the surface to $100 \mathrm{mb}$. There were about 40 levels of data for each sounding. In general, some elements of a sounding were unavailable on just under $10 \%$ of the 92-day period. Missing values were replaced by simple linear interpolation from the surrounding values.

Surface data was gleaned from the monthly Local Climatological Data publications of the National Oceanic and Atmospheric Administration (NOAA). These publications were used to extract daily maximum, minimum, average, normal and dewpoint temperature values as well as precipitation, wind direction, wind speed and sunshine information for the nine stations listed in appendix B.

\section{b. Moisture budget analysis}

Our moisture budget approach is to use the procedure described by Bosart and Sanders (1981) which is modification of Bellamy's (1949) original technique. With the assumption that all condensed water falls out as precipitation, the excess of evaporation $(E)$ over precipitation $(P)$ for a radiosonde station triangle can be written as

$$
\overline{E-P}=\sum_{i=1}^{3} \frac{1}{h_{i}} \int_{100 \mathrm{mb}}^{\bar{p}_{(s f c)}} q_{i} v_{h_{i}} \frac{d p}{g}+\frac{\partial}{\partial t} \int_{100 \mathrm{mb}}^{\bar{p}_{(\mathrm{Scc})}} \bar{q} \frac{d p}{g} .
$$

Here $q$ is the specific humidity, $h$ is the length of the altitude from the vertex to the opposite side and $v_{h}$ is the wind component at the vertex directed outward and parallel to $h$. An overbar denotes an average over the area of the triangle.

According to (1) the areal average excess of evaporation over precipitation $(\overline{E-P})$ at the surface is equal to the vertical integral of the water vapor flux transport (the first term on the right-hand side of $(1), \overline{\nabla \cdot q \mathbf{V}}$ ) plus the local time rate of change of atmospheric precipitable water $(\partial \bar{W} / \partial t)$. The integrated value of $\overline{\nabla \cdot q V}$ can be partitioned into the horizontal advection of water vapor, $\overline{\mathbf{V} \cdot \nabla q}$, and divergence in the presence of water vapor, $\overline{q \nabla \cdot V}$. The subgrid scale moisture flux divergence (eddy flux) cannot, of course, be computed by this method.

The input sounding data (every $50 \mathrm{mb}$ plus significant levels) was vertically interpolated using a "splinein-tension" scheme (Cline, 1974, and NCAR Utility Library) with a tension factor of 1.5 . The vertically integrated divergence was corrected to zero by means of a constant correction according to the method of O'Brien (1970) and Pedder (1981). The quantity $\overline{\nabla \cdot q \mathbf{V}}$ (or $\overline{\mathbf{V} \cdot \nabla q}$ and $\overline{q \nabla \cdot \mathbf{V}}$ ) was averaged over a 12 $\mathrm{h}$ period while $\partial \bar{W} / \partial t$ was taken as the change in precipitable water over the same $12-\mathrm{h}$ period. The results were summed to yield $(\overline{E-P})$. Additionally, kinematic vertical velocity and relative vorticity profiles were determined for each station triangle every $12 \mathrm{~h}$.

Calculations were made for a total of 55 triangles based on the 39 stations in appendix A for the months of June, July and August of 1979 and 1980. In this paper we discuss results for the three areas (average size $4 \times 10^{5} \mathrm{~km}^{2}$ ) shown in Fig. 1. The core of the heat wave and drought is contained within area 1 . Area 2 experiences both extreme heat and higher dewpoint temperatures with modest, but below normal, rainfall. Episodes of extremely hot and dry weather are least frequent in area 3.

\section{c. Evaporation}

The evaporation was estimated independently by means of the advection-aridity approach of Brutsaert and Strickler (1979). Their method combines a potential evaporation estimate (Penman, 1956; Purvis, 1961) with Bouchet's (1963) relationship between potential and actual evaporation to yield:

$$
E=\left(2 \alpha_{e}-1\right)\left(\frac{d e_{s} / d T}{d e_{s} / d t+\gamma}\right) R_{n}-\left(\frac{\gamma}{d e_{s} / d T+\gamma}\right) E_{a},
$$

where $R_{n}$ is the neî radiation near the surface expressed as an equivalent vaporization rate (obtained from the Smithsonian Meteorological Tables) and $E_{a}$, the "drying power" of the air, is given by

$$
E_{a}=0.26\left(1+0.54 \bar{U}_{2}\right)\left(e_{s}-e\right)
$$

where $\bar{U}_{2}$ is the mean wind speed at 2 meters above the surface in $\mathrm{m} \mathrm{s}^{-1}$. The saturation and actual vapor pressure $(\mathrm{mb})$ are denoted by $e_{s}$ and $e$ respectively. The psychrometric constant, $\gamma$, is given by $0.66 \mathrm{mb} \mathrm{K}^{-1}$ and $\alpha_{e}$ is an empirical constant between 1.26 and 1.28 . Brutsaert (1982) noted that the solution of (2) was relatively insensitive to the choice of $\alpha_{e}$ and $E_{a}$.

The advantage of using (2) is that only meteorological parameters are required. Soil moisture data or other measures of aridity are not needed. Other simple potential evaporation formulas might tend to overestimate the evaporation by not considering the shortage of soil moisture (a real problem in much of the Southern Plains in the summer of 1980 as deduced from the crop moisture and Palmer drought indices prepared weekly by the National Oceanic and Atmospheric Administration). We accept a priori, however, that our independent computation of evaporation from (2) is subject to considerable uncertainty.

\section{Climatological overview}

Displayed in Fig. 2 are time series of observed calendar day maximum temperature, dewpoint temperature, mean temperature and the expected climatological average temperature for Tulsa, Oklahoma (TUL); Dallas-Fort Worth, Texas(DFW); Columbia, Missouri (COU); Shreveport, Louisiana (SHV); Atlanta, Georgia 

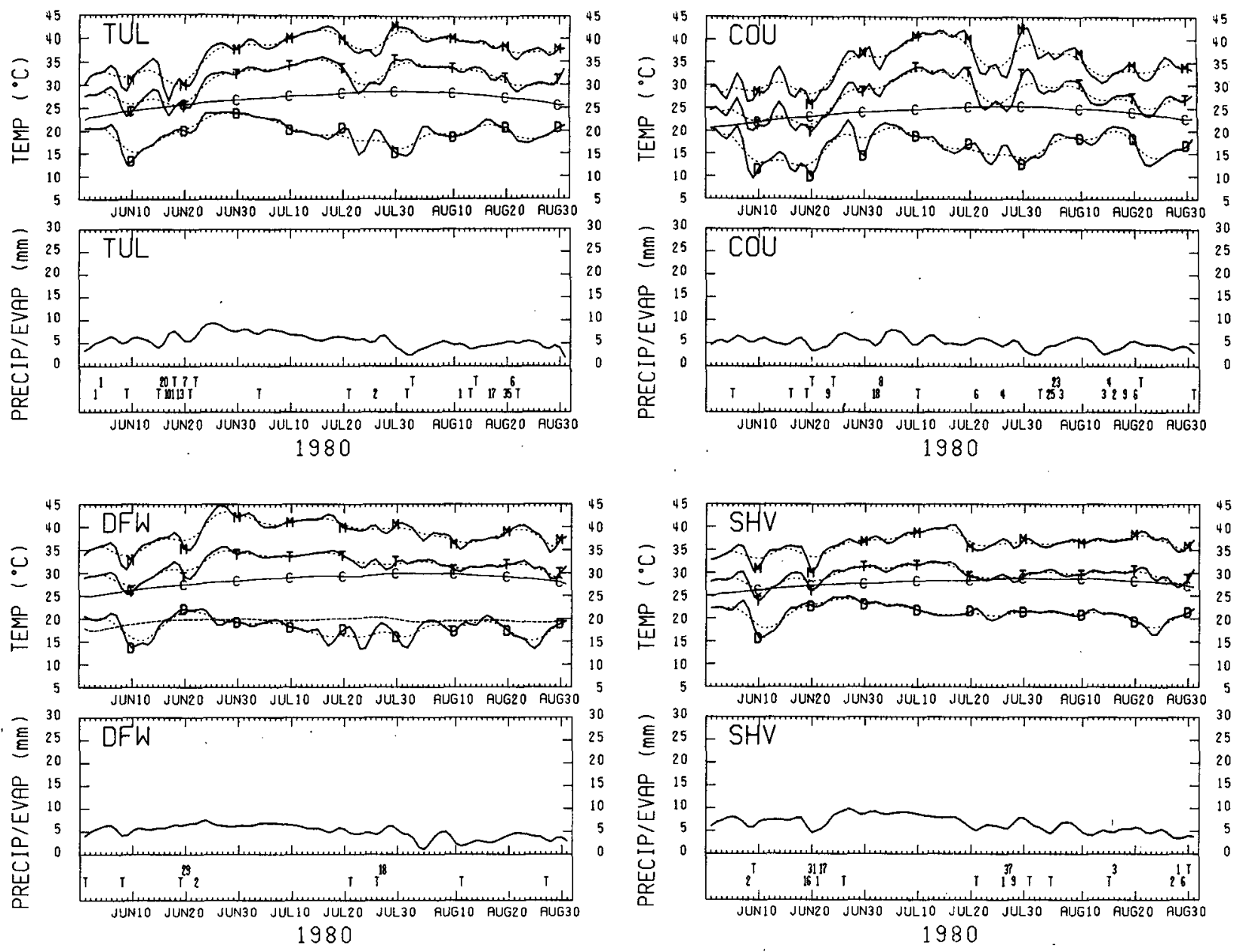

FIG. 2. Top panels: Smoothed (3-point) time series of maximum temperature (M), average temperature $(T)$, dewpoint temperature $(D)$ and climatological mean temperature $(C)$ for the summer of 1980 for TUL, DFW, COU, SHV, ATL and JAN. Units: ${ }^{\circ} \mathrm{C}$. Light dashed lines represent heavily smoothed (11-point) curves. Climatological dewpoint temperature (long-dashed) shown for DFW and JAN. Bottom panels: Smoothed (3-point) time series of estimated evaporation $(\mathrm{mm})$ computed by the advection-aridity method (see text). Calendar day precipitation ( $\mathrm{mm}$ ) appears along the bottom.

(ATL); and Jackson, Mississippi (JAN) for the summer of 1980 . At both DFW and JAN the expected climatological dewpoint temperature is shown as well. Figure 2 includes the observed calendar day precipitation and an independent estimate of evaporation by the advection-aridity approach of Brutsaert and Strickler (1979). The daily values of the meteorological quantities shown in Fig. 2 were smoothed by a simple three point running mean (weights 1-2-1). Additionally, an 11-point filter was applied to the data to identify the principal longterm variations. The filter weights are $0.0166,0.0402$, $0.0799,0.1231,0.1561,0.1684,0.1561,0.1231,0.0799$, 0.0402 and 0.0166 . The response function, $R$, of this low-pass filter is $0.8,0.5$ and close to 0.0 for periods of 16,10 and 5 days respectively. (The source of the filter was the BMDP statistical software, 1985, Uni- versity of California Press, Los Angeles, $734 \mathrm{pp}$, ISBN 0-520-04408-8.)

At both DFW and TUL, in the core of the heat wave area, the 90-day period is noteworthy for the near absence of any days with below average mean temperature. Frontal passages around 10 and 20 June mark temporary interruptions in the building heat wave regime that becomes extreme by late in the month. A sustained period of heat with mean temperatures averaging $5^{\circ} \mathrm{C}$ above normal (according to Namias, 1982 , a $+4.5^{\circ} \mathrm{C}$ anomaly represents more than four standard deviations in this region) is found from late June until 21 July after which time temperatures lower somewhat in the wake of a weak "cool" front passage. During this period there is a clear downward tendency in the average calendar day dewpoint temperature. At DFW 

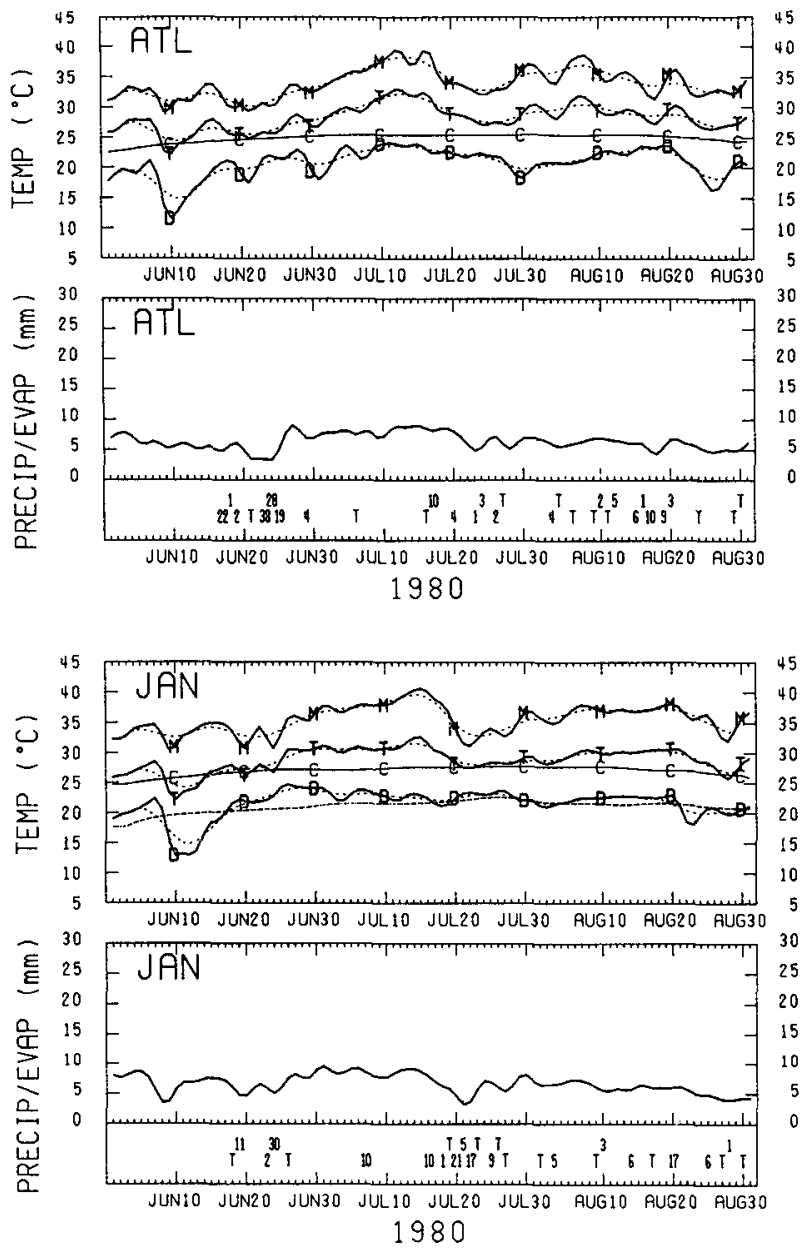

Fig. 2. (Continued)

the slightly above average dewpoint temperatures around 20 June change over to a negative $2^{\circ}-3^{\circ} \mathrm{C}$ anomaly by late July. The dewpoint temperature decrease occurs in the virtual absence of precipitation. A similar pattern is seen at TUL as the dewpoint temperature decreases during a period of sustained high temperatures and scant rainfall. The computed evaporation decrease from $6-7 \mathrm{~mm}$ in late June to 4-5 $\mathrm{mm}$ in late July at both DFW and TUL reflects the drying of the air.

Farther to the east at COU the heat builds a few days later in late June and peaks in the latter half of July. A brief cool spell near 25 July serves only to return the temperature to near normal at COU for a few days. At COU the average dewpoint temperature declines from just over $20^{\circ} \mathrm{C}$ to just under $15^{\circ} \mathrm{C}$ during the month of July under clear skies, negligible precipitation and a sustained period of average temperatures in excess of $7^{\circ}-8^{\circ} \mathrm{C}$ above normal. The passage of a weak trough in the westerlies around 22 July leads to greater temporary cooling at COU compared to TUL. Even though searing heat returns to COU briefly around 30 July, the month of August is characterized by more interruptions of sustained elevated temperatures there than at TUL.

The extreme heat, which pushes individual daily maximum temperatures to near $45^{\circ} \mathrm{C}$ at DFW, TUL and $\mathrm{COU}$, is not as pronounced but shows similar characteristics at SHV which lies to the southeast of the core of the heat wave region. Rainfall at SHV, while concentrated in late June and late July, is still far below normal, and in conjunction with the persistent warmth, the aforementioned dewpoint temperature decrease signal from late June to mid-July is still apparent.

Even at JAN there is evidence for a decrease in dewpoint temperature from late June to mid-July, although, unlike DFW, the decrease does not result in below normal readings. Typically, the dewpoint temperature maximum at JAN is found in late July whereas in 1980 it is found in late June after a period of some precipitation. The decrease in computed evaporation at JAN around 20 July occurs in conjunction with a period of rainfall and does not represent any gradual decrease under dry conditions as seen at TUL, DFW, COU, and to a lesser extent at SHV.

Well to the east at ATL the heat does not build until mid-July. While above normal temperatures prevail in June they are not excessive and the incipient dry period is interrupted by ample rains near the summer solstice. Thereafter precipitation is light and spotty through the end of August with the exception of a small burst in activity around 15 August. Unlike stations farther west (e.g., TUL or COU) the period of highest temperatures around 15 July at ATL coincides with high dewpoint temperatures, leading to a maximum of heat stress on the populace. Although the dewpoint does decrease by $4^{\circ} \mathrm{C}$ by the end of July the decrease occurs in conjunction with a temporary reduction in air temperature. During the first three weeks of August the dewpoint at ATL rebounds as the air temperature once again increases. Overall, the available evidence indicates that even though the air temperature was persistently above normal at ATL (sometimes by more than $5^{\circ} \mathrm{C}$ ) during July and August the relationship of increasing air temperature and decreasing dewpoint temperature seen farther west is not found.

At all six stations (plus others, not shown) the observed precipitation is far less than the computed evaporation for the three-month summer period. The evaporation averages about $5 \mathrm{~mm}$ day $^{-1}$ for inland stations ranging upward to $7 \mathrm{~mm} \mathrm{day}^{-1}$ for locations near the Gulf of Mexico. However, the expected relationship between precipitation and evaporation is seen; there is a decline in evaporation during a precipitation event and an increase of evaporation afterwards.

Figure 3 illustrates the considerable spatial continuity in the dewpoint temperature variations at DFW, TUL and COU. The presence of postfrontal drier air is felt more strongly at $\mathrm{COU}$ around 20 June and briefly again around 30 June. Otherwise the three time series are 


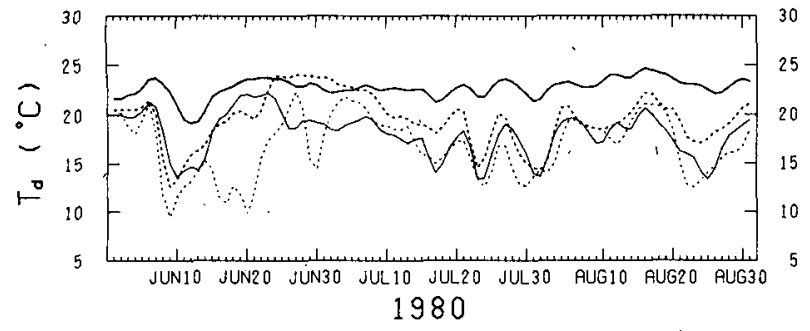

FIG. 3. Smoothed (3-point) time series of surface dewpoint during the summer of 1980 for CRP (thick solid), DFW (thin solid), TUL (thick dashed) and COU (thin dashed). All units ${ }^{\circ} \mathrm{C}$.

very well correlated for the remainder of the summer. The dewpoint temperature increase at DFW, TUL and COU around 20 and 27 July reflects an increase in moisture content ahead of weak frontal troughs. After 1 August the average daily dewpoint temperatures at DFW, TUL and COU rise back to almost $20^{\circ} \mathrm{C}$ where they remain until the next weak frontal passage on 20 August. Even at CRP along the Gulf coast the observed daily dewpoint temperature variation resembles a highly smoothed version of that at DFW, TUL and COU. The dewpoint temperature at CRP decreases roughly $1^{\circ} \mathrm{C}$ from $20 \mathrm{June}$ to $20 \mathrm{July}$ and then increases again by $\sim 1.5^{\circ} \mathrm{C}$ to a maximum around 17 August.

Figure 4 depicts the average daily meridional component of the geostrophic wind, constructed as the difference between the mean sea level pressure at Corpus Christi, Texas (CRP) and Apalachicola, Florida (AQQ) for June, July and August 1980 . Broadly speaking, Fig. 4 shows a southerly transport from the Gulf of Mexico across $30^{\circ} \mathrm{N}$ for the entire summer. A temporary interruption in this southerly flow occurs around 10 June as a weak cold front reaches the Gulf coast with lesser interruptions in the latter part of June. During the first half of July the southerly flow weakens and even reverses to very weak northerly around 14 July as the heat builds over the continent and the dewpoint temperatures lower (Figs. 2 and 3). The strengthening southerly geostrophic flow around 20 and 27 July corresponds to the twin dewpoint surges seen at this time

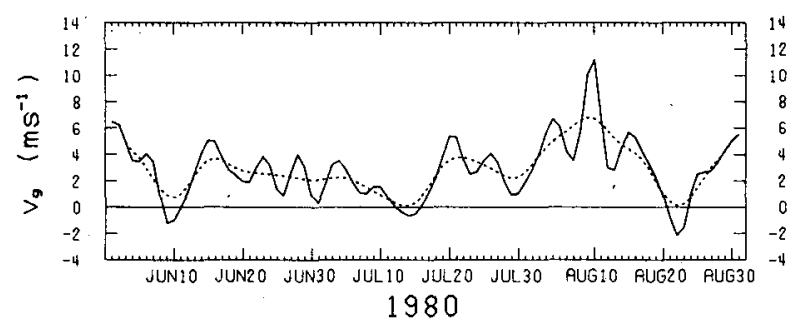

FIG. 4. Smoothed time series (solid, 3 points; dashed, 11 points) of the meridional component of the surface geostrophic wind $\left(\mathrm{m} \mathrm{s}^{-1}\right)$ computed from the Apalachicola, FL (AQQ)-Corpus Christi, TX (CRP) pressure difference. in Fig. 3. The strongest southerly flow in the summer of 1980 occurs in the first half of August during which time the dewpoint temperatures recover to near or slightly above normal levels.

Finally, Fig. 5 depicts the observed and normal daily temperature range as well as daily maximum and minimum temperature anomalies for TUL, DFW, COU and JAN. At DFW the worst of the heat wave occurred from 25 June to $18 \mathrm{July.} \mathrm{During} \mathrm{this} \mathrm{period} \mathrm{the} \mathrm{diurnal}$ temperature range anomaly averaged $5^{\circ} \mathrm{C}$. The anomaly was produced by excessive maximum temperatures, particularly at the outset of the period. There is no compelling evidence for a simultaneous increase of diurnal temperature range and decrease of minimum temperature with the observed dewpoint temperature decrease at DFW. Unlike DFW, the average daily temperature range at TUL was close to normal most of the summer. Both the maximum and minimum temperatures were equally excessive from 25 June to 20 July at TUL. Comparison with Fig. 4 shows that dew-
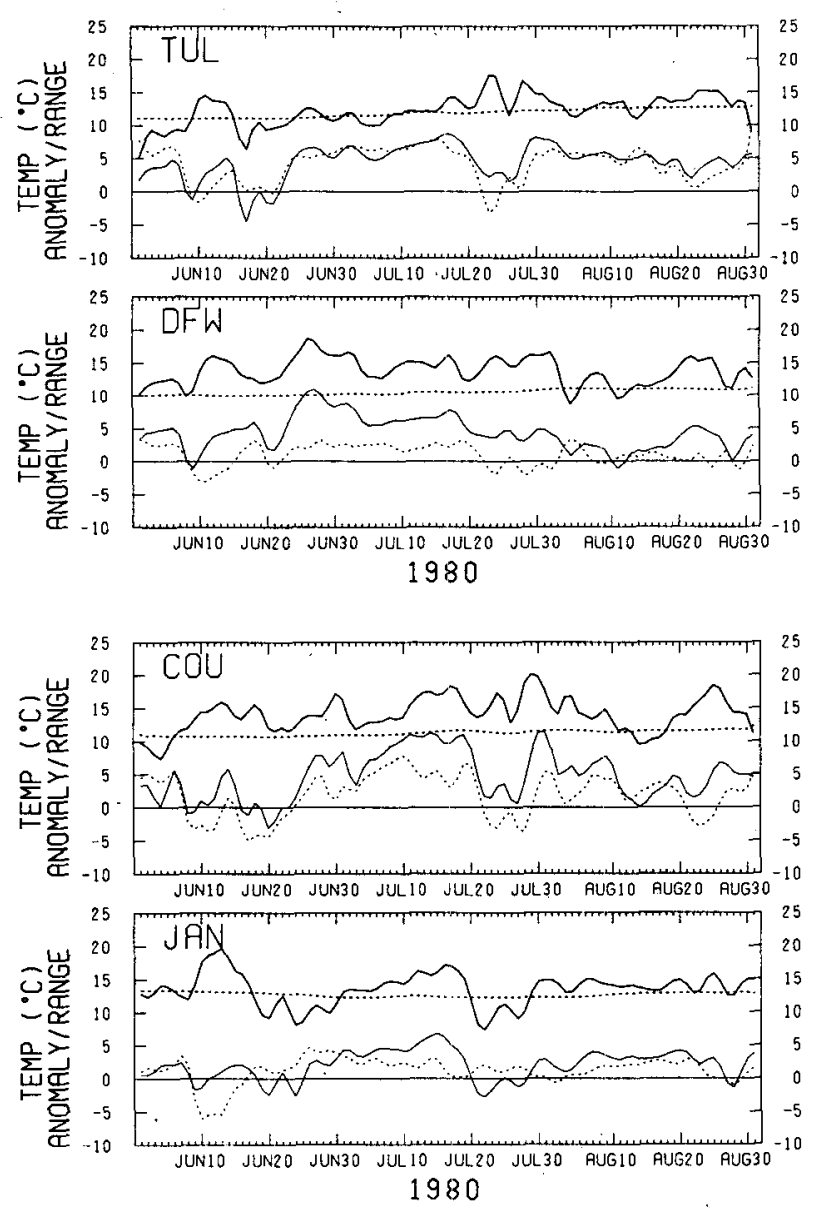

FIG. 5. Smoothed (3-point) summer 1980 time series of: (top of each panel) observed daily temperature range (solid) and climatological daily temperature range (dashed); (bottom of each panel) daily maximum (solid) and minimum (dashed) temperature anomaly for TUL, DFW, COU and JAN. All units ${ }^{\circ} \mathrm{C}$. 
point temperatures averaged $2^{\circ}-3^{\circ} \mathrm{C}$ higher at TUL than DFW although the trend is identical over the late June to late July period. Heat stress was definitely a problem at TUL during the summer of 1980 . (The maximum temperature was above normal from 22 June through 31 August.)

At COU there is weak evidence for a gradual increase in daily temperature range from late June to late July (briefly interrupted by the frontal passage from 22-26 July). The diurnal temperature range at COU is mostly influenced by the maximum temperature anomaly during the critical period. Meanwhile the heat wave period of 25 June to 20 July at JAN features a steady increase in the daily temperature range from below normal to above normal. The increase is sustained by steadily increasing maximum temperature anomalies in conjunction with slowly decreasing positive minimum temperature anomalies. According to Fig. 2 the dewpoint temperature anomaly at JAN decreases from $2^{\circ}-3^{\circ} \mathrm{C}$ to nearly zero over this period. Prior to the rainy period around $20 \mathrm{July}$ at JAN there is reasonable evidence that the slowly increasing daily temperature range under heat wave conditions is driven by maximum temperature anomalies. The minimum temperature anomaly decreases as the air dries out. Farther west at DFW this signal is not observed. Perhaps the difference can be explained by differences in vegetation types and soil moisture reserves.

\section{Moisture budget results}

Time series of vertically integrated $\mathrm{V} \cdot \nabla q$ and $q \nabla \cdot \mathrm{V}$ at 0000 and 1200 UTC for areas 1,2 and 3 during the years 1979 and 1980 respectively are shown in Figs. 6 and 7. In 1980 the net advection of water vapor, $V \cdot \nabla q$, contributes to drying at 0000 UTC with an average value of $\sim 1.5 \mathrm{~mm}$ in area 1 . There are twin surges of drying of $\sim 4.0$ and $3.0 \mathrm{~mm}$ respectively around 25 June and 3 July as the heat wave intensifies. Moistening by advection is infrequent in area 1 . In area 2 there is net drying at 0000 UTC from 20 June to 20 July followed by moistening $(\sim-2.0 \mathrm{~mm}$ ) through 10 August. Moistening and drying by $\mathbf{V} \cdot \nabla q$ alternate in area 3 for 0000 UTC. The 1200 UTC $V \cdot \nabla q$ results also exhibit net drying of $\sim 1.0 \mathrm{~mm}$ for all three regions. While there is no coherent pattern to the area 3 signal, the period from late June to early July exhibits net drying of $\sim 4.0 \mathrm{~mm}$ in areas 1 and 2 at the outset of the heat wave. The $\mathbf{V} \cdot \nabla q$ results for 1979 differ only slightly from 1980. In general, there is slightly less net drying in 1979. In both years there appears to be a slight diurnal variation in $\mathbf{V} \cdot \nabla q$ in areas 1 and 2 with relatively more moistening indicated at 1200 UTC. For example note the 1200 UTC tendency for net moistening by advection in 1979 for area 1 from mid-July to midAugust.

The dominant contributor to drying in area 1 (and to a lesser extent area 2 ) is divergence in the presence

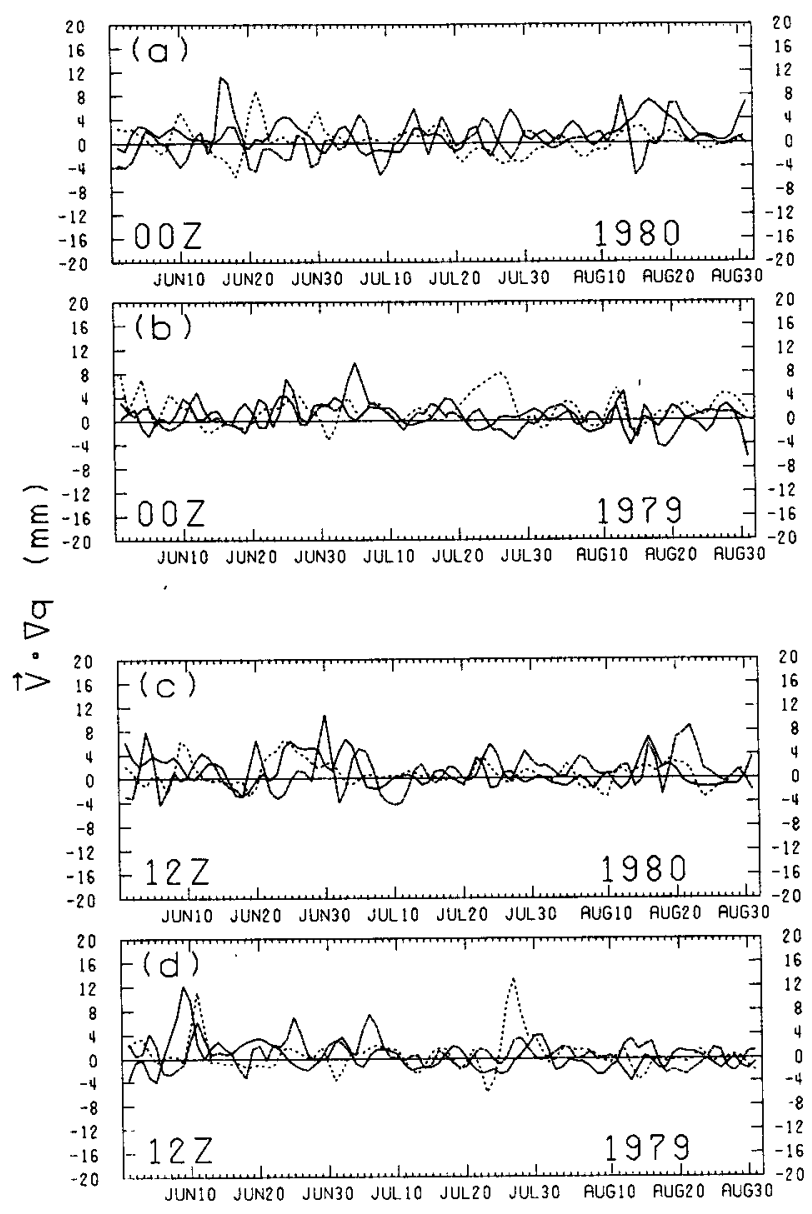

FIG. 6. Smoothed (3-point) time series of vertically integrated $\mathrm{V} \cdot \nabla q$ $(\mathrm{mm})$ in areas 1 (solid), 2 (short dashed) and 3 (long dashed) for (a) 0000 UTC 1980, (b) 0000 UTC 1979, (c) 1200 UTC 1980 and (d) 1200 UTC 1979. Areas as shown in Fig. 1.

of water vapor, $q \nabla \cdot \mathrm{V}$, at $0000 \mathrm{UTC}$. Comparison with the 1200 UTC results reveals the presence of a prominent diurnal cycle in the $q \nabla \cdot \mathrm{V}$ term (except in area 3). Drying is either lessened or replaced by moistening at 1200 UTC. The contribution to drying by divergence averages almost $8.0 \mathrm{~mm}$ at 0000 UTC in area 1 from 30 June to $20 \mathrm{July}$, a period of extreme heat and decreasing dewpoint temperature. A similar sustained period of drying due to divergence is found in area 2 with an abrupt transition to moistening around $20 \mathrm{July}$ as a synoptic-scale system crosses the region. Comparison of the 1979 and $1980 q \nabla \cdot V$ results reveals that the diurnal oscillation is present both years in areas 1 and 2 and there are more frequent moistening episodes associated with migratory synoptic systems in 1979.

Figure 8 displays the computed excess of evaporation over precipitation from (1) in all three areas for 1979 and 1980 . From 10 June to 20 July area 1 is much drier in 1980 than 1979. During the remainder of the summer the computed $(E-P)$ is mostly positive in both years with only very infrequent interruptions of 

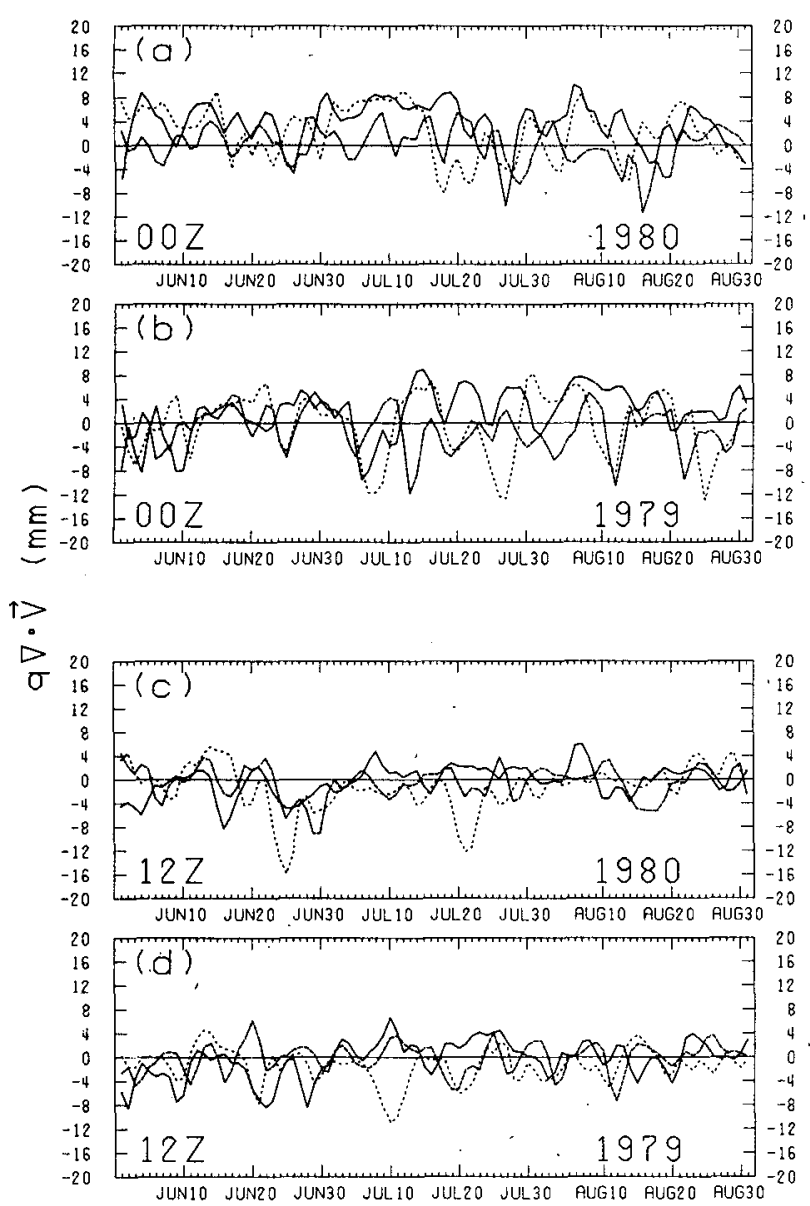

FIG. 7. As in Fig. 6 except for $q \nabla \cdot V$.

$(E-P) \sim 0$ or negative. The long dry period from late June to mid-July is also seen in area 2 for 1980 . In contrast note that $(E-P)$ alternated sign frequently in area 2 in 1979. Clearly the summer of 1980 in the Southern Plains (area 1) began with a prolonged period of $(E-P)>0$ which set the stage for soil moisture depletion and then intensified in July and August as there was only one period of $(E-P)<0$ in late July. In contrast, the portion of the southeastern United States represented by area 3 had the most frequent episodes of $(E-P)<0$ in both 1979 and 1980, particularly in 1979 . Very hot episodes in 1980 were occasionally tempered by rainy periods although much of July and the first part of August were dry.

\section{Profiles of vertical velocity, divergence, and relative vorticity}

Time series of 500 and $850 \mathrm{mb}$ vertical motions at 0000 and 1200 UTC are shown in Figs. 9 and 10 for all three areas in 1980 and 1979 , respectively. In 1980 descending motion prevails most of the time at both isobaric levels for area 1 at 0000 UTC. In general, the computed descent is greater at $500 \mathrm{mb}$ which supports divergence in the 850-500 mb layer and the formation of a subsidence inversion. It also verifies the computed moisture divergence and $(E-P)>0$ for area 1 for 20 June to 20 July (Figs. 7 and 8 ). Comparison of the 0000 and 1200 UTC verticall motions gives evidence for an appreciable diurnal variation in 1.980 in area 1 . In general there is reduced subsidence and enhanced ascent at 1200 UTC at both 850 and $500 \mathrm{mb}$. The diurnal variation in vertical motion, while strongest at 500 and $700 \mathrm{mb}$ (not shown), is still evident at 850 mb. Roughly half the time the 1200 UTC time series of vertical motion for area 1 shown in Fig. 9 implies convergence in the $850-500 \mathrm{mb}$ layer in strong contrast to the pervasive divergence present in the same layer at 0000 UTC. Comparison of both the 0000 and 1200 UTC area 1 vertical motion patterns reveals short periods of ascent in mid- and late June and again in late July which coincide with the infrequent precipitation outbreaks in area 1 (e.g., see DFW and TUL in Fig. 2). Area 2 is similar to area 1 in that there is greater subsidence at 0000 UTC. The breakdown of the synoptic-scale ridge in area 2 after $17 \mathrm{July}$ is manifested by the onset of frequent periods of $500 \mathrm{mb}$ ascent until the end of the month with no sustained periods of descent for the remainder of the summer. A strong diurnal variation in ascent is found in area 2, particularly from 20 June to $20 \mathrm{July}$, with ascent generally computed at 1200 UTC. The passage of weak synoptic-scale systems around 20 June and 20 July reinforces the area 2 ascent. Apparently afternoon and early evening subsidence was particularly effective in suppressing convection (especially in area 2) during the critial heat wave period from late June to mid-July.

The 1979 vertical motion time series in areas 1 and
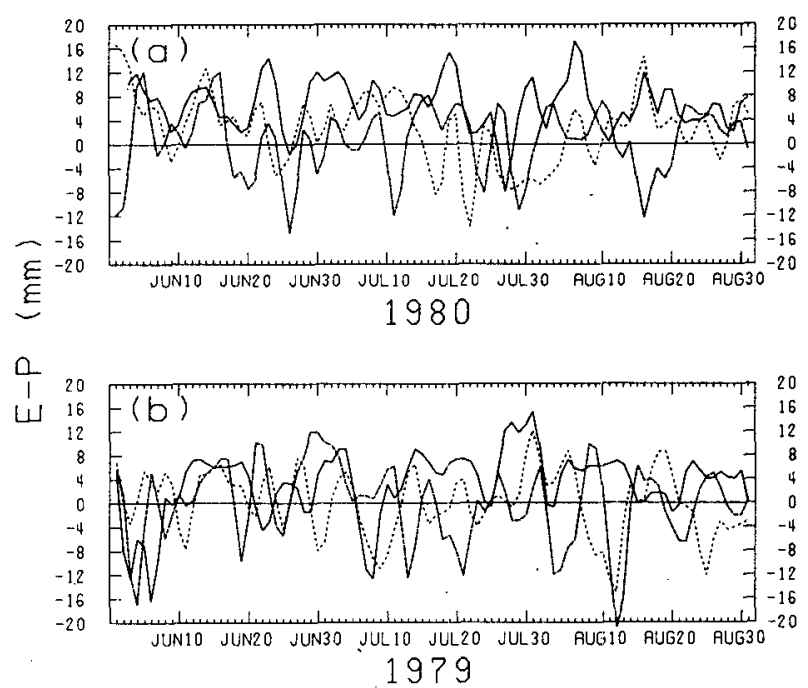

FIG. 8. Computed evaporation minus precipitation $(E-P)$ in $\mathrm{mm}$ for areas 1 (solid), 2 (short dashed) and 3 (long dashed) for (a) 1980 and (b) 1979. All curves smoothed by a 3-point filter. 




FIG. 9. Smoothed (3-point) time series of kinematic vertical motion [mb (12 h) $)^{-1}$ ] for areas 1 (solid), 2 (short dashed) and 3 (long dashed) during the summer of 1980 for (a) $500 \mathrm{mb} 0000 \mathrm{UTC}$, (b) $500 \mathrm{mb}$ 1200 UTC, (c) $850 \mathrm{mb} 0000 \mathrm{UTC}$ and (d) $850 \mathrm{mb} 1200$ UTC.

2 differ in two important aspects from the 1980 results. First, there is less descent overall and, second, there appear to be more frequent interludes of changes in the magnitude and sign of the vertical motion in response to a stepped up frequency of passage of synoptic weather systems through the region. Although the aforementioned diurnal signal is still present in 1979, there is reduced descent and more frequent ascent at 1200 UTC.

In contrast, area 3 (Figs. 9 and 10 ) features the regular passage of synoptic-scale weather systems as there are numerous oscillations of the sign of the vertical motion for both years. Likewise there is no distinct diurnal vertical motion signal in either year. We conclude that the diurnal vertical motion variation decreases eastward from the Southern Plains to the Atlantic coast. Figures 9 and 10 also imply that the diurnal variation in divergence exceeds the synoptic-scale signal in areas 1 and 2 during 1980. Exceptions occur around 20 June and 20 July with the passage of weak synoptic-scale disturbances. In general, divergence is pervasive at 0000 UTC with convergence more likely at 1200 UTC.

The corresponding 500 and $850 \mathrm{mb}$ relative vorticity profiles are presented in time series format for all areas during the summer of 1980 in Fig. 11. Anticyclonic relative vorticity dominates both the 0000 and 1200 UTC time series with a slight tendency for the $850 \mathrm{mb}$ relative vorticity to be more anticyclonic at 1200 UTC. AT $500 \mathrm{mb}$, the period from 22 June to 18 July coincides with pronounced anticyclonic relative vorticity in areas 1 and 2 as the continental anticyclone in the middle troposphere becomes well entrenched. A gradual eastward movement of the anticyclone is implied during this period. Comparison with Fig. 2 shows that excessive maximum temperatures are recorded at TUL and DFW during this three-week period. The onset of cyclonic vorticity at $500 \mathrm{mb}$ in area 2 after 20 July coincides with the temporary breakdown of the anticyclone. There is little indication of a diurnal variation

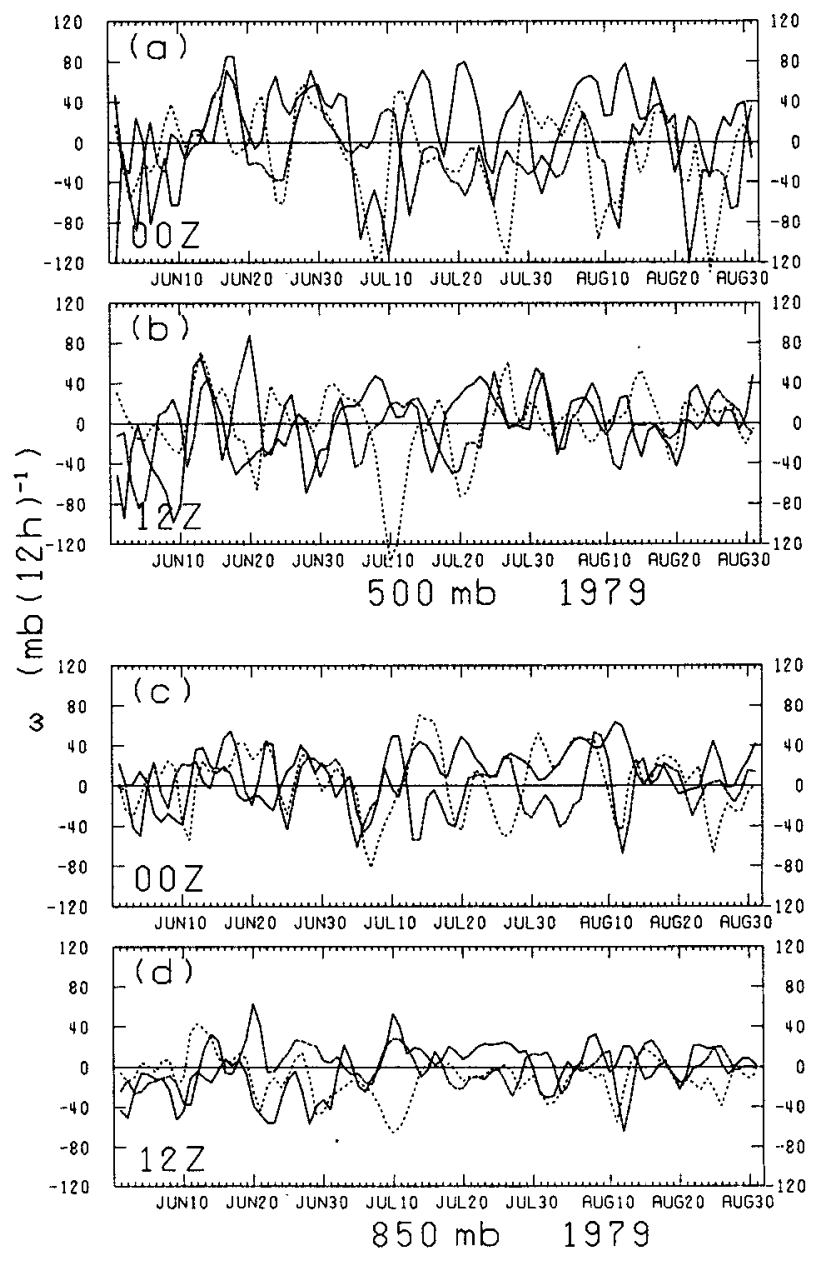

FIG. 10. As in Fig. 9 except for 1979. 


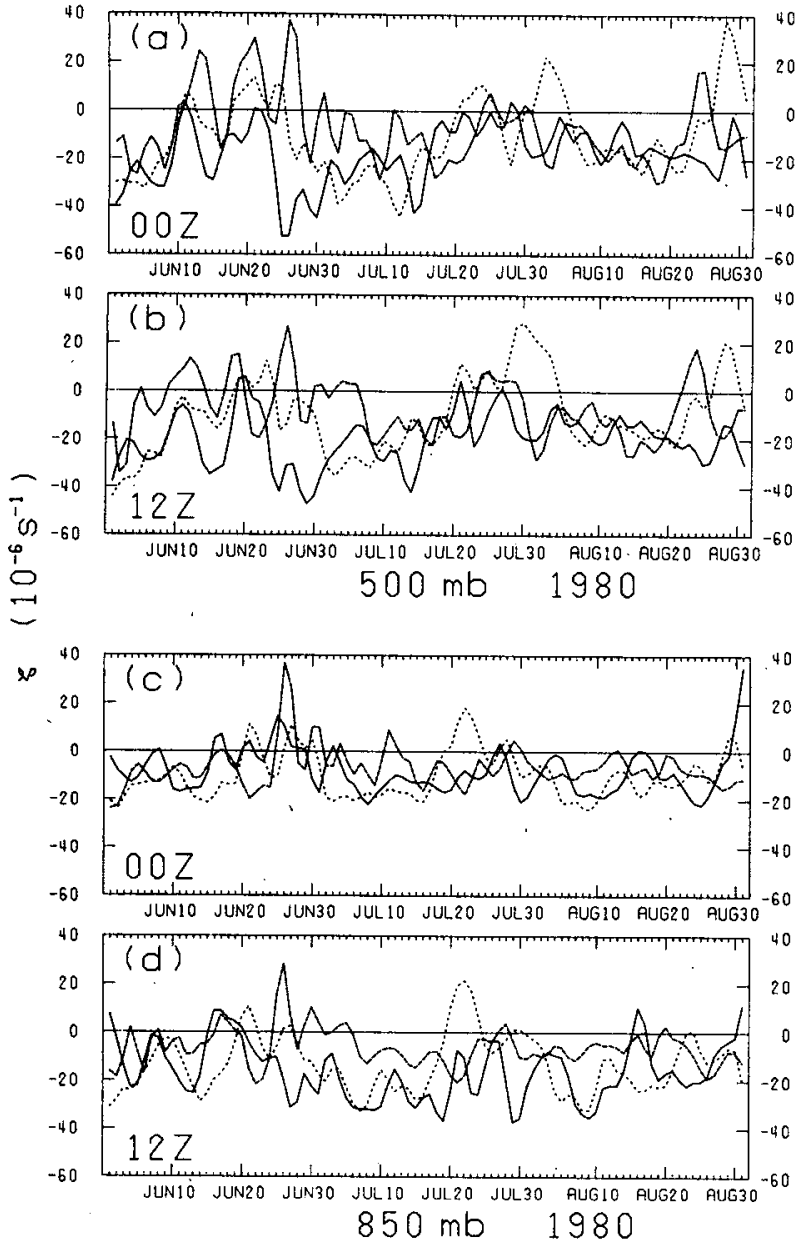

FIG. 11. As in Fig. 9 except for relative vorticity $\left(\times 10^{-6} \mathrm{~s}^{-1}\right)$ for the summer of 1980 .

of $500 \mathrm{mb}$ vorticity. However, to the extent that the relative vorticities displayed in Fig. 11 can be considered geostrophic there is an implied diurnal variation in thermal vorticity with the thermal vorticity being most anticyclonic at 0000 UTC.

From 20 June to 15 August there is no $850 \mathrm{mb}$ cyclonic circulation in area 1 at 1200 UTC. A similar statement can be made for area 2 from 28 June to 22 August with the exception of the 20-30 July period. The 0000 UTC $850 \mathrm{mb}$ relative vorticity remains anticyclonic, but less so, in both areas while farther east in area 3 there is little evidence for a diurnal signal.

\section{Monthly sounding analysis}

Figures 12-14 depict the July 1979 and 1980 mean temperature and dewpoint temperature profiles for areas $1-3$, respectively. The temperature values were derived from averaging the 0000 and 1200 UTC readings. The corresponding winds were averaged from the 0000 UTC data alone. The outstanding temperature characteristic of all three regions is the increased warmth in July 1980 (particularly in region 1, the westernmost region) relative to July 1979 below 400 mb. The excess warmth in 1980 is most pronounced near the surface, reaching $5^{\circ} \mathrm{C}$ in area 1 . A secondary area of relative warmth in 1980 is found in the 250$150 \mathrm{mb}$ layer. Similarly the 1980 mean soundings are characterized by lower specific humidities everywhere except in the surface to $800 \mathrm{mb}$ layer of regions 2 and 3 where little change is seen. Given the warmer planetary boundary layer temperatures in these regions, however, the mean soundings display lower relative humidities at all levels.

The area 1 mean winds remain light and veer upward (warm advection sense) in both years. The surface and $900 \mathrm{mb}$ winds are slightly stronger and more westerly in July 1980 as compared to July 1979 in area 1 which is suggestive of a more continental air source in the former month. To the east, in area 2, the July 1980 winds back (cold advection sense) above $700 \mathrm{mb}$ from easterly to northwesterly. Evidently the mean mid-tropospheric ridge line in July 1980 lies between areas 1 and 2. Stronger July winds are seen in both years in area 3 with more northwesterly flow in the 900-500 mb layer in 1980 when the continental anticyclone is well established upstream.

Figure 15 shows the mean $\theta, \theta_{e}$ and $\theta_{e s}$ profiles for the months of June, July and August in area 1 for 1980 and 1979. Conditional instability is found below 500 $\mathrm{mb}$ for both years and all months. In 1980 the level of free convection (LFC) is lower only in June for area 1. The 1980 profiles also indicate that 1980 is less conditionally unstable than 1979 , particularly below 750 $\mathrm{mb}$. More significant, however, is the fact that $\theta_{e s}$ is much greater than $\theta_{e}$ in 1980 than in 1979, which indicates less chance for release of the conditional instability. The anemic synoptic-scale systems in area 1 during the summer of 1980 were incapable of lifting surface air to the LFC. Surface parcels when lifted (constant $\theta_{e}$ ) will achieve buoyancy in $1980(1979)$ at the $570 \mathrm{mb}(540 \mathrm{mb}), 575 \mathrm{mb}(655 \mathrm{mb})$ and $615 \mathrm{mb}$ $(690 \mathrm{mb})$ during June, July and August respectively.

The vertical profiles of $\theta, \theta_{e}$ and $\theta_{e s}$ shown in Fig. 15 resemble similar profiles for a tropical atmosphere found in Ooyama (1969). There are important differences, however. The continental $\theta_{e s}$ profiles shown in Fig. 15 are much warmer than their tropical counterparts, particularly in 1980 when $\theta_{e s}$ exceeds $390 \mathrm{~K}$ in July below $900 \mathrm{mb}$ (typical tropical values are $365 \mathrm{~K}$ ). The continental midtropospheric minimum $\theta_{e s} \sim 340$ $\mathrm{K}$ in the $500-400 \mathrm{mb}$ layer is comparable to tropical values. Consequently, surface parcels must be lifted to considerably lower pressures over the continent than the typical value of $900 \mathrm{mb}$ characteristic of much of the tropics before convection can begin. In both years convection (in the mean sense) is relatively easier to initiate as the summer wears on. Widespread subsidence in the lower and midtroposphere (recall Figs. 9 


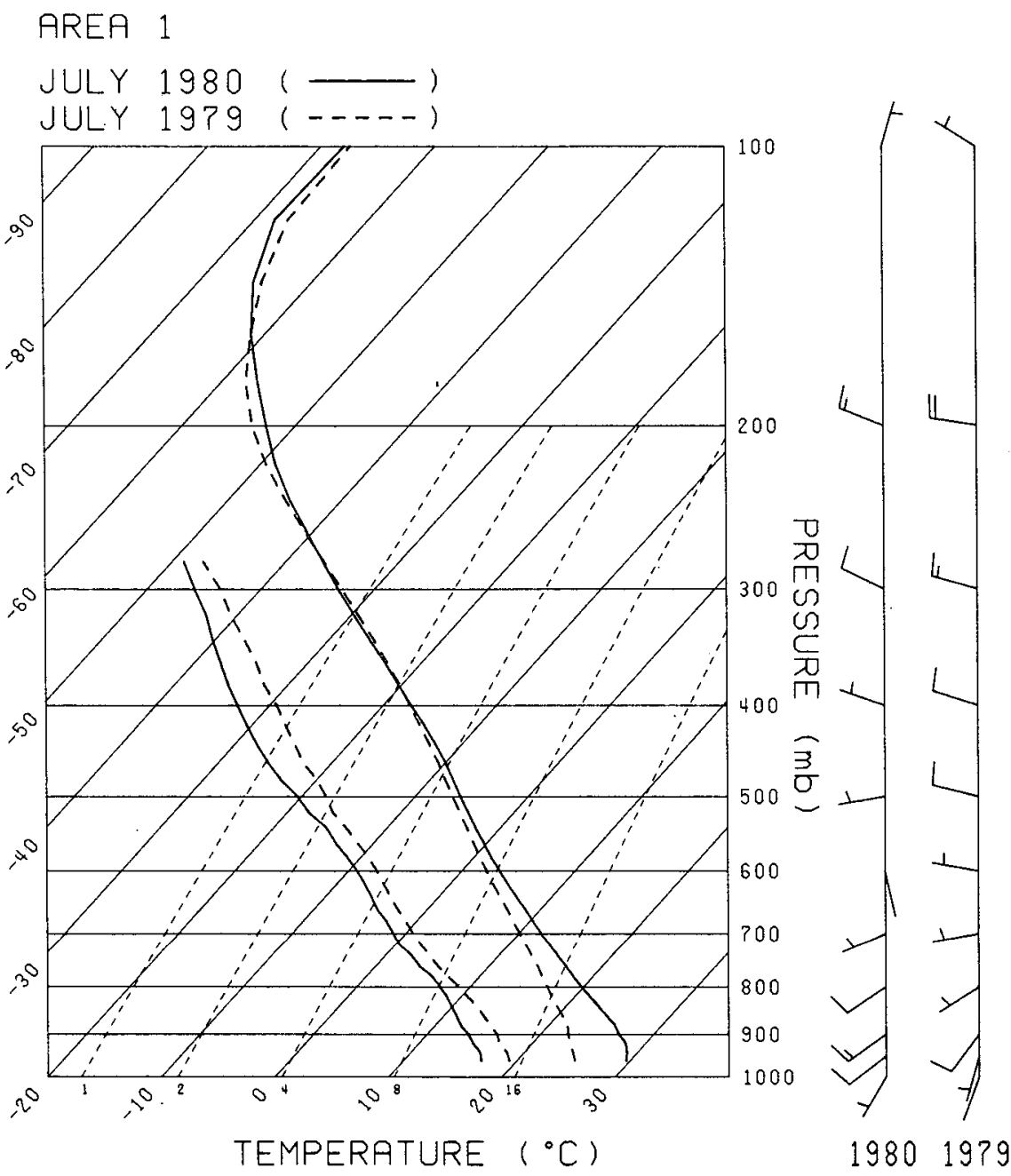

FIG. 12. Mean July temperature and dewpoint temperature soundings composited from 0000 and 1200 UTC data for area 1 for 1980 (solid) and 1979 (dashed). Skew $T-\log p$ format. Plotted winds $\left(\mathrm{m} \mathrm{s}^{-1}\right)$ for 0000 UTC data only with one full barb and half barb denoting $5 \mathrm{~m} \mathrm{~s}^{-1}$ and $2.5 \mathrm{~m} \mathrm{~s}^{-1}$ respectively.

and 10) during much of the summer of 1980 in conjunction with the continental anticyclone precludes the occurrence of convective episodes.

\section{Concluding remarks}

\section{a. Diurnal variation}

Previous investigators (e.g., see Rasmusson, 1968; Holton, 1967; Blackadar, 1957; Wallace, 1975; Bonner, 1968; Reiter and Tang, 1984) have established that there is a diurnal variation in precipitation, moisture flux convergence, vertical velocity and boundary layer horizontal wind in much of the Great Plains and adjacent Rocky Mountain region, particularly during the warm season. Physical mechanisms responsible for producing low-level daytime divergence and nighttime convergence over the central United States include the diurnal variation of differential heating over sloping terrain (Holton, 1967; Reiter and Tang, 1984), the diurnal variation of frictional drag within the planetary boundary layer (Blackadar, 1957), or a combination of both mechanisms in conjunction with the inertial wind cycle in the Southern Plains to account for the characteristic strengthening of the low-level jet in the hours prior to sunrise. More recently, Uccellini (1980) has pointed out the importance of synoptic-scale control on the location and intensity of low-level jets in the central United States through vertically coupled ageostrophic circulations accompanying propagating jet streaks.

In order to examine more closely the vertical structure of the diurnal variation, we present in Figs. 16 and 17 ten-day averaged vertical profiles of vertical motion and relative vorticity for 0000 and 1200 UTC in area 1 for the summers of 1979 and 1980 . The 0000 


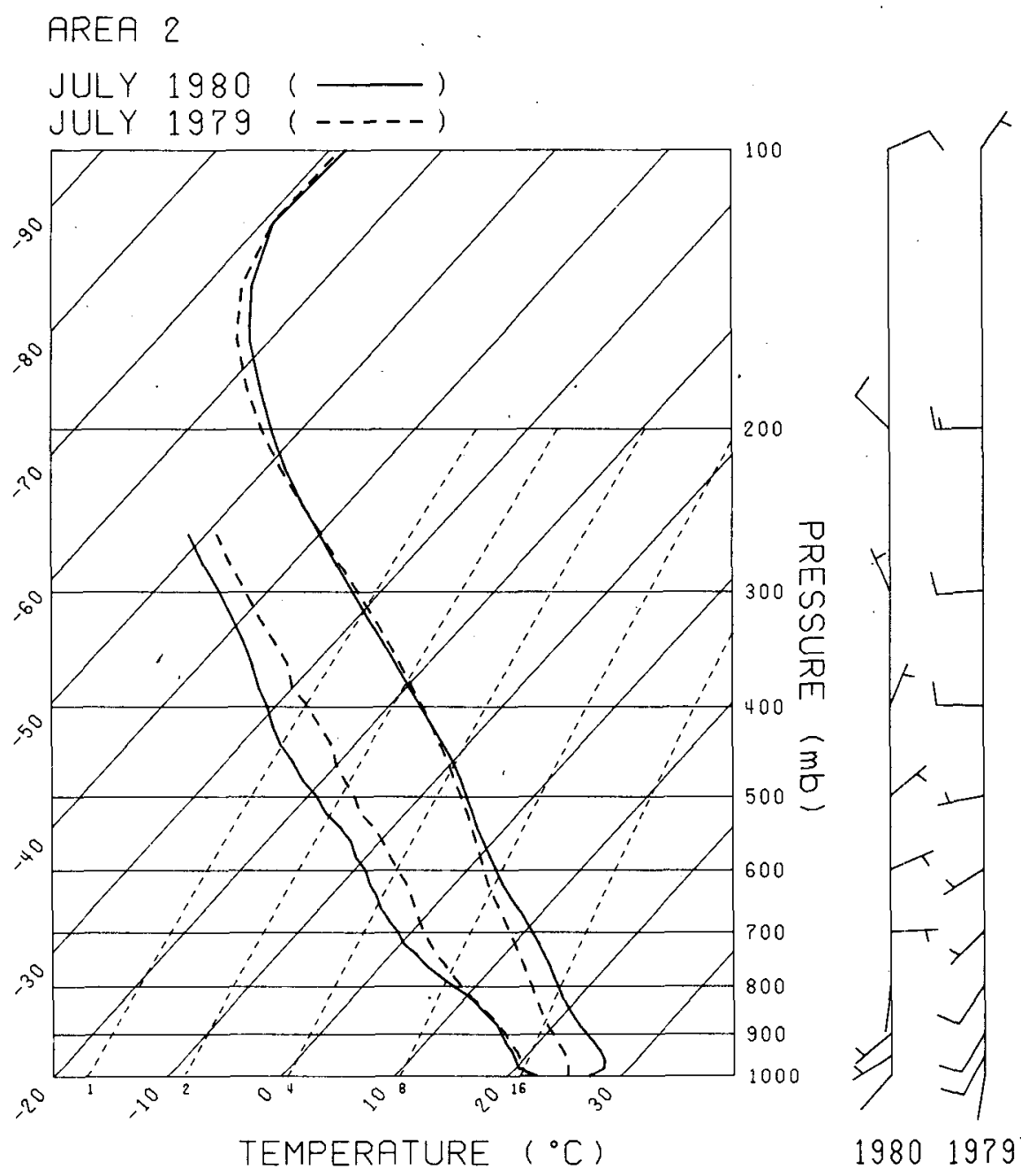

FIG. 13. As in Fig. 12 except for area 2.

UTC vertical motion profiles (Fig. 16) are characterized by descent, especially in 1980, throughout much of the troposphere. Particularly noteworthy is the intense subsidence, peaking in the 700-600 mb layer, from 120 July as the continental anticyclone strengthens. The 0000 UTC results disclose that from 11 June to 20 July the level of maximum subsidence lowers from 400 to $650 \mathrm{mb}$, which implies an increase of divergence in the lower troposphere.

A dramatic difference is seen in the 19801200 UTC vertical motion profiles. Gone is the deep 0000 UTC subsidence throughout the troposphere through 20 July. The change is most pronounced near $700 \mathrm{mb}$ where strong subsidence at 0000 UTC vanishes or is replaced by ascent at 1200 UTC. The changeover occurs in both years but is most noticeable in 1980 . Simply stated, the dominant area 1 signal in 1980 at 1200 UTC must be one of convergence in the $900-700 \mathrm{mb}$ layer from 1 June to 20 July. This layer of convergence is overlain by a weaker, and deeper, layer of divergence so that ascent in the time averaged sense is not seen above $500 \mathrm{mb}$. The LFC (Fig. 15) in 1980 remains above the layer of ascent at 1200 UTC in the climatological sense so that late-night convective systems are not favored. An exception to this pattern occurs from 11-20 June 1980 when deep ascent is computed. Mention has already been made how the late June period coincides with the passage of one of the last active synoptic systems in area 1 during the summer of 1980 .

The 1200 UTC profiles of vertical motion in 1979 differ from 1980 in two important respects. First, there is less subsidence in the mid- and upper troposphere in early and late June. Second, from 21 June through $20 \mathrm{July}$, subsidence is lessened or ascent is strengthened below $700 \mathrm{mb}$. While the diurnal signal of increased low-level ascent at 1200 UTC is still found in 1979, it is reduced considerably from 1980 . Also of interest is the 1200 UTC subsidence centered near $875 \mathrm{mb}$ from $1-20$ July and again from 31 July-9 August 1980 . This feature has no real counterpart in 1979. The presence 


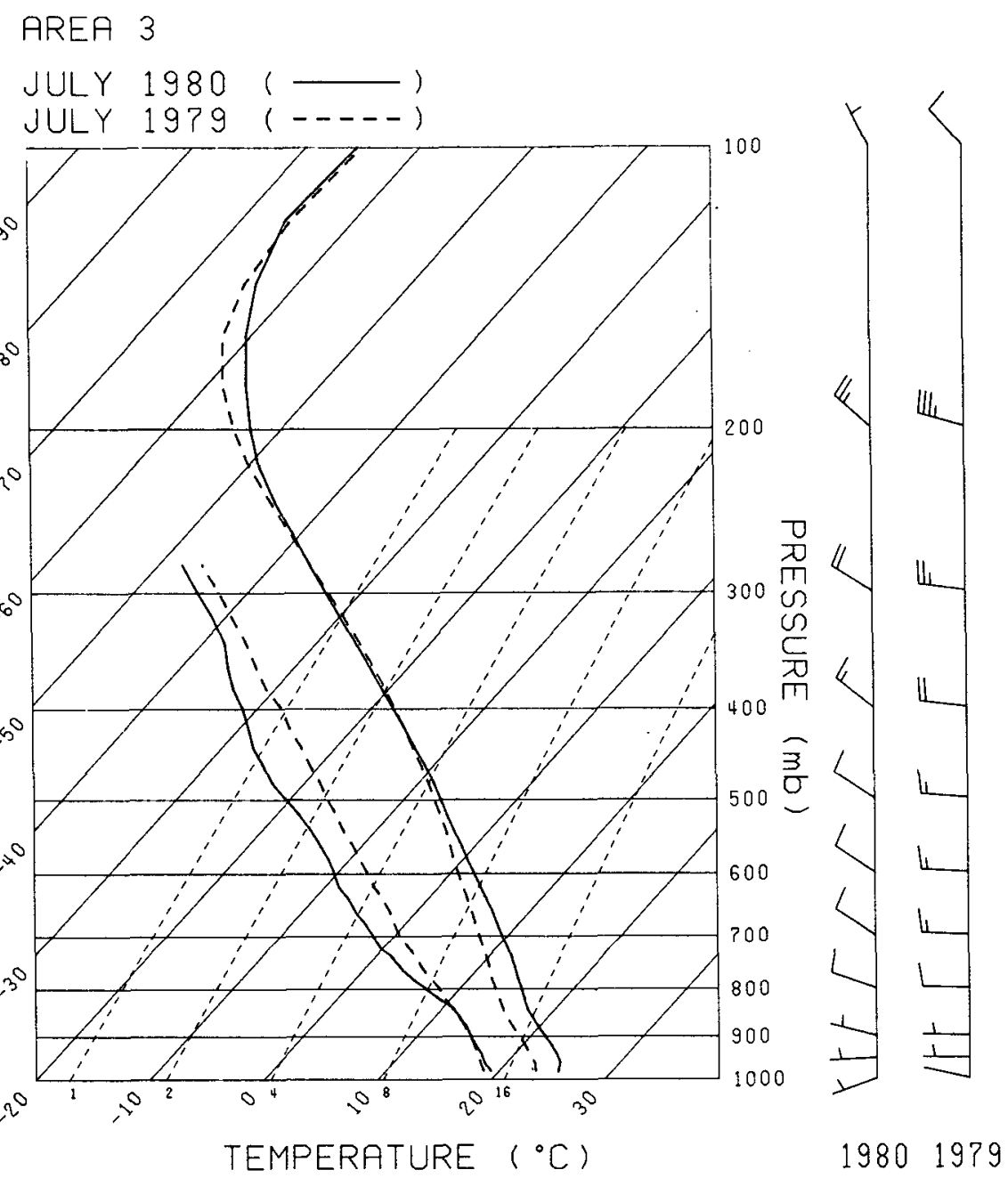

FIG. 14. As in Fig. 12 except for area 3.

of a subsidence maximum at $875 \mathrm{mb}$ implies that existence of shallow $100 \mathrm{mb}$ layer of divergence adjacent to the ground. Again the formation of convective weather systems in a low-level divergence regime is not favored.

The corresponding relative vorticity profiles displayed in Fig. 17 show the widespread anticyclonic relative vorticity that characterized almost the entire troposphere at both 0000 and 1200 UTC during the summer of 1980 in area 1. The anticyclonic relative vorticity tends to maximize in the upper troposphere during June while a secondary maximum appears in July in the 900-800 mb layer, especially at 1200 UTC. At the surface cyclonic relative vorticity is occasionally seen at 1200 UTC (e.g., 1-10 and 21-30 June, 11-20 July and 10-19 August) but not at 0000 UTC except from 21-30 June when there was a frontal passage through area 1 . In 1979 much less anticyclonic vorticity is found, particularly in the mid- and upper tropo- sphere. There is little direct evidence for a diurnal variation in relative vorticity at any level in 1979.

Figure 11 reveals the existence of a diurnal variation of $850 \mathrm{mb}$ relative vorticity from 20 June to 10 Augus $t$ 1980. Anticyclonic relative vorticity is maximized near $850 \mathrm{mb}$ at 1200 UTC during the first part of the summer of 1980 . Noteworthy is the area 1 anticyclonic relative vorticity maximum in the lower troposphere at 1200 UTC from 1-20 July. We have no explanation for the "spike" of cyclonic relative vorticity near 875 $\mathrm{mb}$ that is depicted at 1200 UTC in most of the average profiles in Fig. 17 except to note that it appears to be a real feature in the data. We speculate that the lobe of lower-tropospheric anticyclonic vorticity found at 1200 UTC in early and mid-July may be a manifestation of anticyclonic vorticity generation due to strong subsidence maximizing at $700 \mathrm{mb}$ the previous 0000 UTC. Perhaps anticyclonic vorticity, once produced by horizontal divergence, is maintained as the bound- 

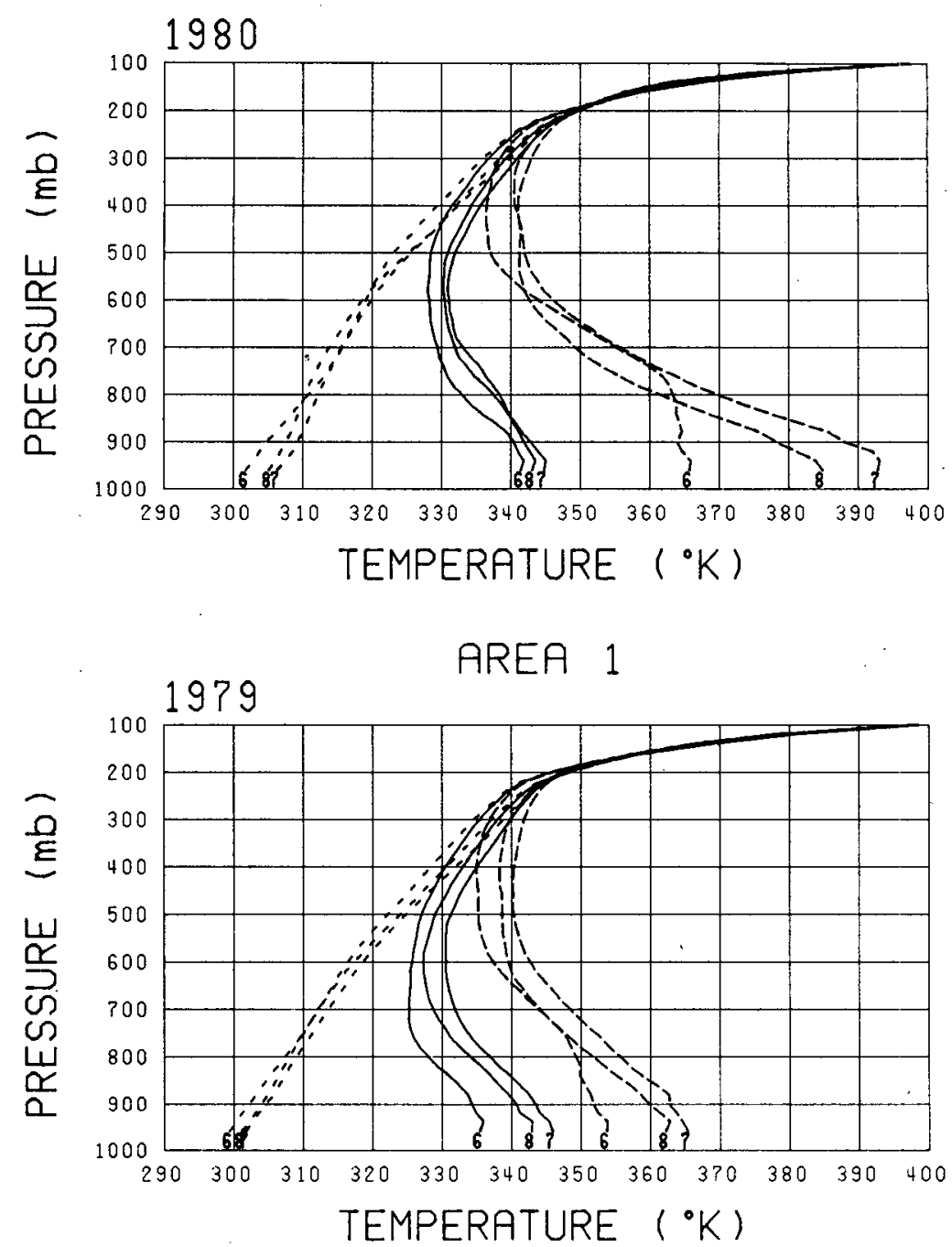

FiG. 15. Area 1 June (6), July (7), and August (8) vertical profiles of potential temperature (short dashed), equivalent potential temperature (solid) and saturation equivalent potential temperature (long dashed) for (top) 1980 and (bottom) 1979.

ary layer air is decoupled from the free atmosphere after sunset. As surface dewpoints lowered in area 1 during the first half of July, there would be an increasing tendency to form a nocturnal inversion at night as the air dried out.

Our previous results have established that the summer of 1980, a very hot and dry period in the Southern Plains, differs from the summer of 1979 , a slightly cooler and wetter than normal period, in terms of the frequency of synoptic-scale weather changes and the magnitude of the diurnal variation of vertical motion and moisture divergence. In both summers there is a tendency for more convergence (or reduced divergence) and ascent (or lessened subsidence) in much of the lower and midtroposphere at 1200 UTC as compared to 0000 UTC. We see evidence for the familiar nighttime convergence and daytime divergence in the Southern Plains that has been amply documented else- where (e.g., Wallace, 1975; Reiter and Tang, 1984). In 1980 , however, the diurnal signal is amplified substantially from 1979 in our target areas in the Southern Plains and lower Mississippi River Valley. The diurnal variation in vertical motion, amounting to $2-3 \mathrm{~cm} \mathrm{~s}^{-1}$, maximizes in the 700-650 mb layer. We suggest that the much greater strength of the diurnal variation in vertical motion, divergence, and moisture divergence across the Southern Plains during the summer of 1980 is a direct response to the clear skies and high insolation under the persistent continental scale anticyclone regime. Put simply, there is broad low-level divergence over the Plains by day as air is forced to approach and ascend the intensely heated Rocky Mountains to the west.

At night the circulation attempts to reverse with reduced lower-tropospheric divergence. There are isolated periods of weak convergence and ascent with weak 

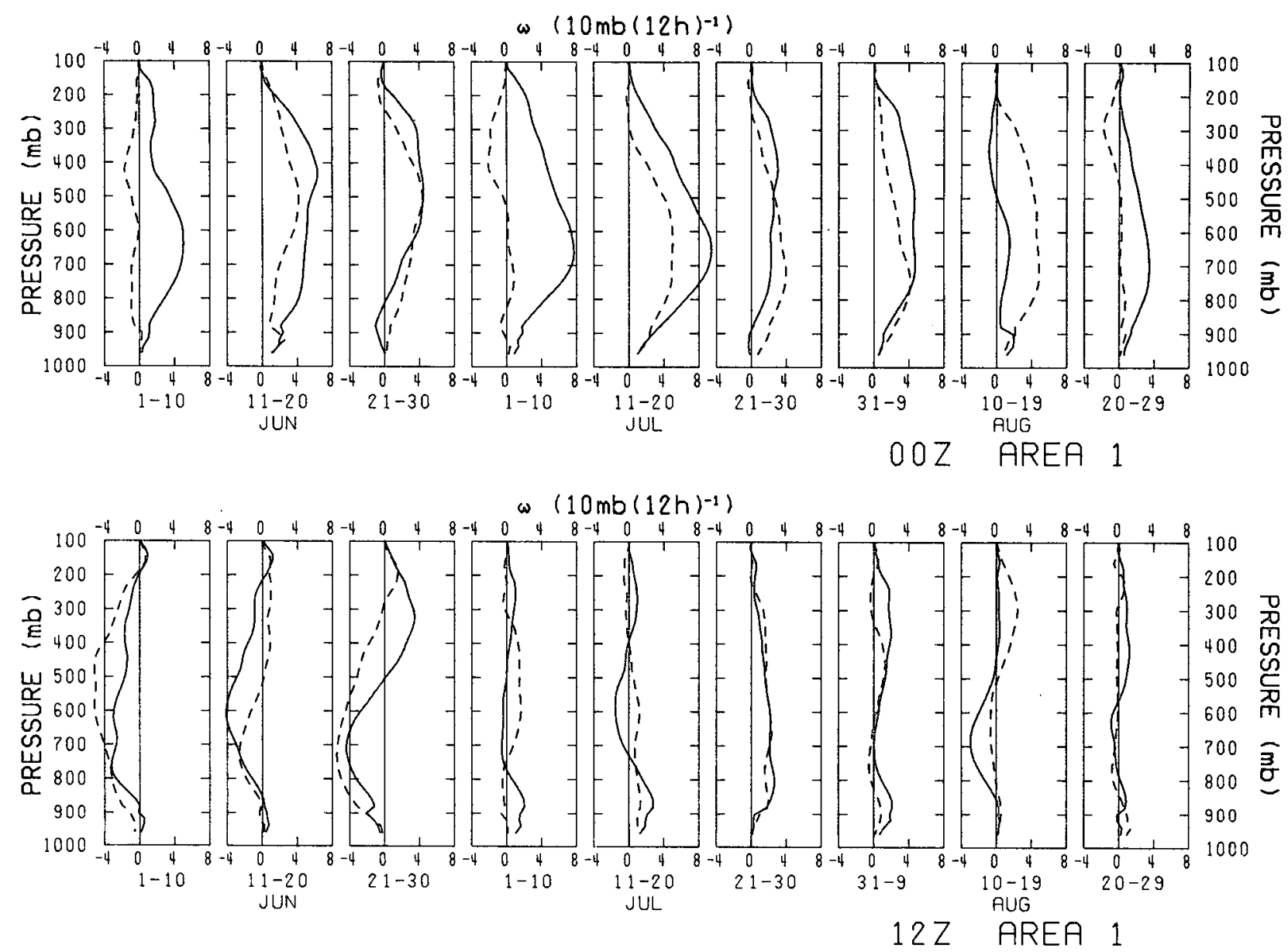

FIG. 16. Area 1 ten-day average profiles of vertical motion for 0000 (1200) UTC top (bottom). Results for 1980 (1979) given by solid (dashed) lines. Units: $\mathrm{mb}(12 \mathrm{~h})^{-1}$.

surface cyclonic relative vorticity that mostly correspond to the time of passage of synoptic-scale disturbances. The location of the level of maximum diurnal variation just above $700 \mathrm{mb}$ from late June to late July 1980 may reflect the mean height of the Rocky Mountains to the west. Below the mean elevation of the Continental Divide, the diurnal variation of the east-west thermal gradient will be a maximum. It is possible that the observed intense diurnal variation in subsidence aloft over the Southern Plains during the summer of 1980 is driven by the diurnal variation of surface and planetary boundary layer divergence arising from differential sensible heating over sloping terrain.

An alternate explanation is that the circulation over the Southern Plains during the summer of 1980 is part of a massive heat low circulation over the intensely heated continent. Blake et al. (1983) and Smith $(1986 \mathrm{a}, \mathrm{b})$ in a study of the Arabian heat low, found nighttime divergence and subsidence through much of the troposphere with shallow near surface daytime convergence and ascent. The 1200 UTC and 0000 UTC soundings sample atmospheric conditions shortly be- fore sunrise and just after the time of maximum surface heating respectively. There is no compelling evidence for daytime ascent and nighttime descent for sustained periods in 1980 in either the Southern Plains or lower Mississippi River Valley. Rather, the tendency to generate very weak cyclonic vorticity near the surface at 1200 UTC in 1980 can be viewed as a manifestation of a broad diurnal circulation with airflow toward the mountains by day and away from the mountains at night as described by Wallace (1975). It is also possible that the nature of our analysis technique has precluded us from capturing the heat low circulation if it is present.

During the summer of 1980 strong subsidence by day, under the persistent continental scale anticyclone aloft, resulted in intense heating and drying of the overlying air mass. Because of the considerable difference between the equivalent and saturation equivalent potential temperatures, the level of free convection was quite high across the Southern Plains compared to normal. Afternoon and early evening deep convection was either eliminated or suppressed in the absence of 

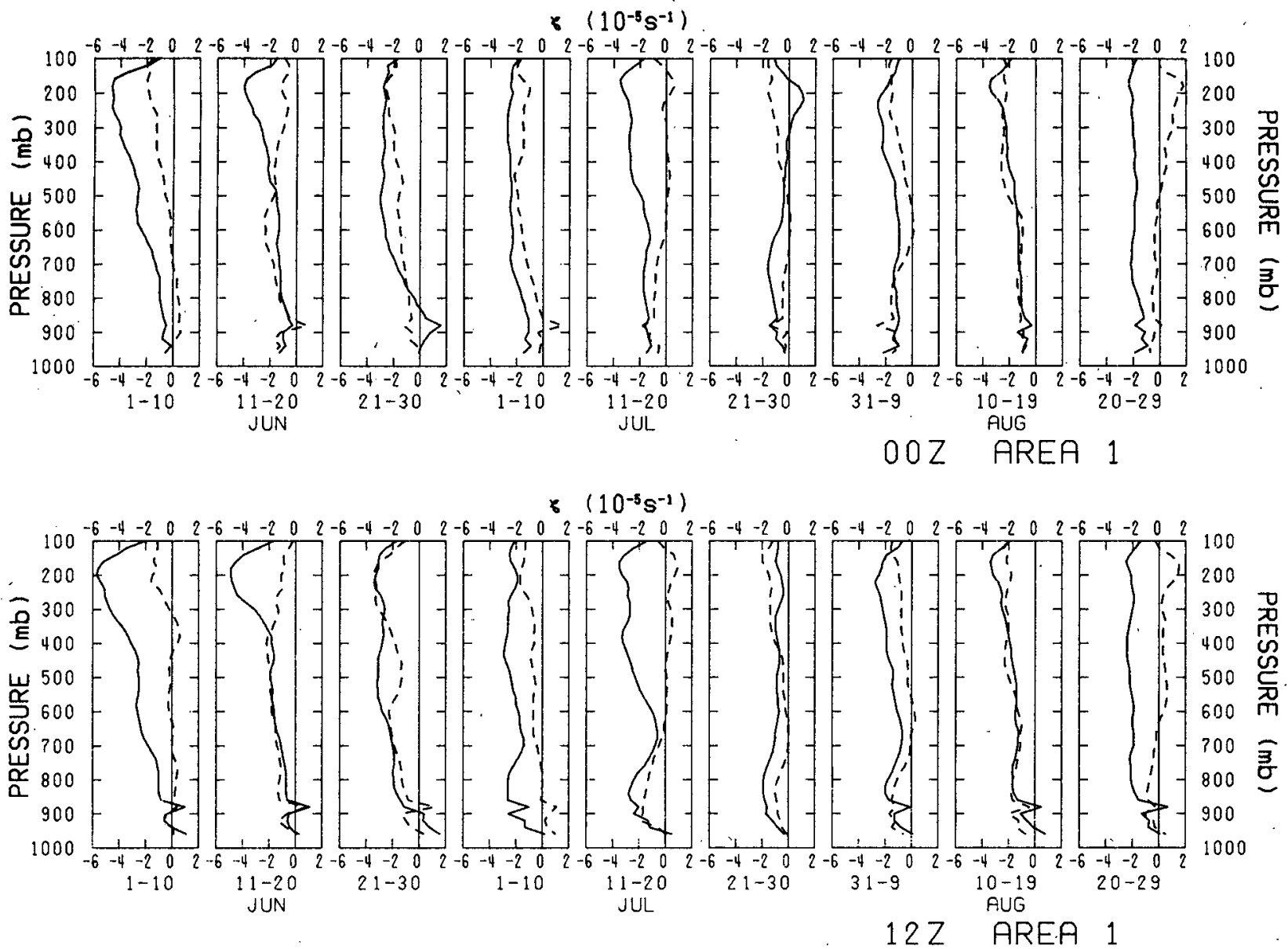

FIG. 17. As in Fig. 16 except for relative vorticity. Units: $10^{-5} \mathrm{~s}^{-1}$.

synoptic and subsynoptic scale lifting mechanisms. Few, if any, low-level boundaries were then available to persist overnight and serve as a triggering and focusing mechanism for new convective elements with the reversal of the diurnal circulation to produce nighttime convergence. Unfortunately, across much of the Southern Plains from late June to late July 1980, the reversal of the diurnal circulation was weak and sporadic and there was insufficient lifting to trigger outbreaks of organized mesoscale convective systems. The existence of low-level anticyclonic relative vorticity centered near $850 \mathrm{mb}$ at 1200 UTC during much of this period also contributed to the prevention of deep inflow and ascent.

\section{b. Evaporation}

Figure 18 displays a time series of evaporation computed by adding the average observed daily precipitation (22 stations) to the $(E-P)$ calculation from the moisture budget equation (1) in area 1 for the summers of 1980 and 1979. For comparison purposes the evaporation, estimated from the advection-aridity approach from (2), is given for an average of DFW, ICT and TUL in Fig. 18. Likewise for the potential evaporation calculated from pan observations (observed value times a pan coefficient, 0.8 for summertime, see Howell et al., 1983) and the observed precipitation based upon a 22 station network within area 1 . As might be expected, there are considerably more fluctuations in the daily evaporation computed from the budget results than the other methods. However, it is clear that on a number of days the evaporation computed from (1) lies in the $10-15 \mathrm{~mm}$ range (overall average is $\sim 8 \mathrm{~mm}$ ) superposed over a decreasing trend from late June to late July 1980 which coincides with the period of presumed soil moisture depletion and withering vegetation. In contrast, during 1979 the computed evaporation averages closer to $5 \mathrm{~mm}$ (the lower troposphere is less divergent) with a brief period near $20 \mathrm{~mm}$ in the middle of a wet period around 30 July.

During July and August 1980 the observed pan evaporation substantially exceeds the estimated [from (2)] and computed evaporation. As noted by Monteith (1981), the pan evaporation method overestimates the evaporation in regions where vegetation is periodically 

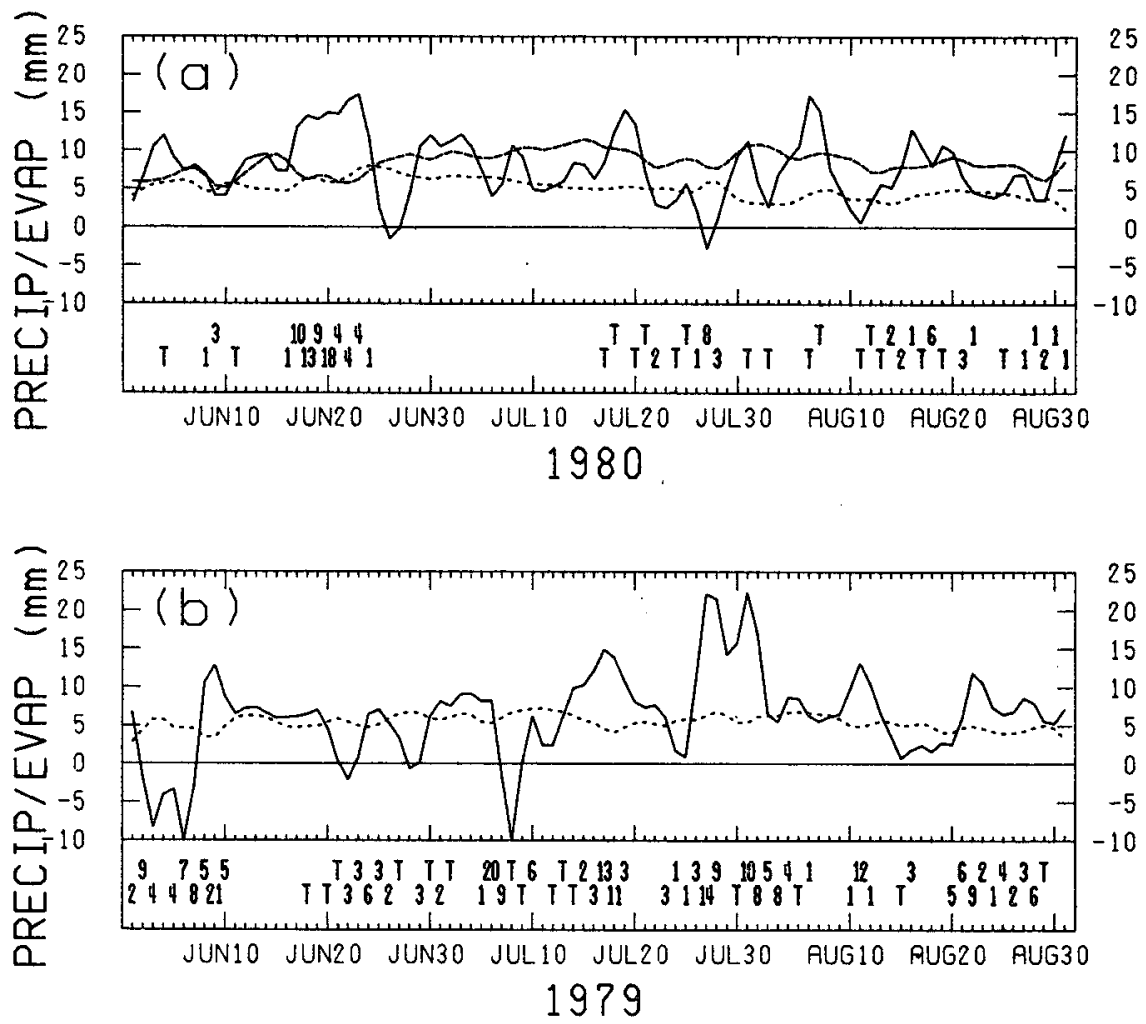

FIG. 18. (a) Smoothed (3-point) time series of computed evaporation (solid), estimated evaporation (short dashed) and observed pan evaporation (long dashed) in area 1 for the summer of 1980; (b) As in (a) except for the summer of 1979. Observed pan evaporation not available. Units: $\mathrm{mm}$. Areal averaged ( 22 stations) observed precipitation $(\mathrm{mm})$ appears along the bottom.

short of water; as the actual rate of evaporation from the area decreases, the atmosphere becomes drier and the pan evaporation increases. However, it may be possible to think of the evaporation obtained from pan observations as an upper limit to the actual evaporation. The evaporation estimated by the advection-aridity approach has its own limitations. When the air temperature exceeds $30^{\circ} \mathrm{C}$, the Bowen ratio for equilibrium evaporation (see Priestly and Taylor, 1972) becomes negative and implies large-scale advection. This violates one of the assumptions used in constructing the model and according to Brutsaert and Strickler (1979) the resulting effect warrants further investigation.

Comparison of the 1980 computed and estimated evaporation in Fig. 18 shows some modest agreement despite the aforementioned limitations. The linear correlation coefficient between these two curves is 0.25 (caution, the two datasets are not completely independent) and the computed evaporation is generally larger than the estimated evaporation. During select periods, for example, around 20 June, the computed evaporation exceeds the observed pan evaporation. It is possible that the computed evaporation has been overestimated. This can happen if our 22 station network overesti- mates the actual areal averaged precipitation during a period of convection such as took place near 20 June. It is also possible that an overestimate of the moisture flux divergence, $\nabla \cdot q \mathbf{V}$, can lead to an overestimate of evaporation from (1). Just how such an overestimate can arise is not completely clear but we note that the diurnal variation in $q \nabla \cdot V$ is appreciable in area 1 and it is quite possible that the twice per day atmospheric sampling has resulted in aliasing in the computation of evaporation from (1). Indeed, Rasmusson (1968) has established the presence of a systematic error pattern in $\nabla \cdot q \mathrm{~V}$ and that the use of only twice daily observations to define the daily flux over the region of strong diurnal variation in the flux may be one important source to the systematic error pattern.

We conclude that evaporation played an important role in the climate and weather over the Southern Plains during the summer of 1980. During June, when there was no appreciable soil moisture shortage, surface evaporation attempted to balance the drying of the atmosphere due to large-scale subsidence as the continental anticyclone intensified aloft. Precipitation was suppressed, and without adequate rain the soil moisture was probably depleted rapidly under the intense solar insolation. Ultimately the evaporation rate declined. 
With continued intensification of the continental anticyclone aloft during July and little if any precipitation over a wide area of the Southern Plains, many crops perished and much of the vegetation withered. Without adequate evaporation from the dry soil, nearly all of the available solar insolation went into sensible heating and excessive surface temperatures became widespread. A positive feedback process resulted because divergence in the lower troposphere (below $850 \mathrm{mb}$ at $1200 \mathrm{UTC}$; below $600 \mathrm{mb}$ at 0000 UTC) resulted in large-scale subsidence which contributed to further drying and warming of the atmosphere. Particularly apparent was the cessation of much of the nocturnal precipitation so characteristic of much of the region. From late June through much of July both dynamic and thermodynamic processes combine to suppress precipitation while evaporation under intense solar heating leads to soil dessication.

Namias (1962) was one of the first people to recognize the linkage between soil moisture availability, drought, protracted heat waves and continental anticyclones during the warm season. He suggested that a knowledge of soil moisture availability might have predictability applications on the climate time scale over the Great Plains. These ideas have formed the basis of recent modeling, observational and theoretical research on a widespread variety of problems ranging from desertification and deforestation to seasonal climate forecasts (e.g., see Charney, 1977; Mintz and Shukla, 1982; Rowntree and Bolton, 1983; Gutman, 1984; Yeh et al., 1984; Walsh, 1986). A common theme of these investigations is that a decrease in evaporation leads to a decrease in precipitation and the eventual generation of a surface heat low with ascending motion in the lower troposphere. Our results are not in agreement with this model in that there is little direct evidence for a heat low circulation during much of the summer in our chosen area of interest in the Southern Plains. Our conclusion is rather weak, however, because the twice daily sampling at 1200 and 0000 UTC is not ideally suited for the resolution of a heat low circulation and our results may be contaminated by aliasing.

Modeling studies such as Rowntree and Bolton (1983) and Yeh et al. (1984) have suggested that a local soil moisture anomaly can have an impact on rainfall a few days later and will spread out following the largescale motion and may persist for several months. More recently Anthes and Kuo (1986) have used a mesoscale model to simulate the impact of soil moisture anomalies on three day forecasts over North America. They found significant circulation differences across the region as a function of the imposed evapotranspiration cycle. The findings of Anthes and Kuo (1986) suggest that the distribution of soil moisture anomalies may have a significant impact on short term forecasting. Supporting evidence comes from Maddox et al. (1981) in studies of severe storms in Colorado. They found instances where moisture that fueled Colorado severe storms originated in evapotranspiration over the Central and Northern Plains. Instances were noted of surface dewpoint temperature increases (in the presence of ample soil moisture) across the Great Plains following cold front passages where there was no evidence for the return of moisture by advection from the Gulf of Mexico. We suggest that there is much that can be learned from further numerical experimentation and testing of scientific hypotheses for the summer of 1980 drought case.

The protracted heat wave and drought did not break down until well into August when the large-scale pattern changed so as to allow the weakening of the continental anticyclone. From late June through much of August there were only infrequent passages of synoptic-scale weather systems across the Southern Plains. None of these systems produced sufficient precipitation in terms of areal coverage or amount to alter the soil moisture budget anomaly significantly. Consequently the prevailing pattern of desiccation, drought and heat was always regenerated in a planetary circulation regime favorable for a persistent anticyclone aloft over the Southern Plains.

Acknowledgment. We thank John Molinari, Jon Scott, Howard Bluestein and the-anonymous referees for their critical comments. The upper air data was provided by NCAR and most of the critical computations were done at NCAR. The text was prepared by Carol Tennant. The research was supported in part by NSF Grant ATM802655702 and NOAA Grant NOAA3205151A.

\section{APPENDIX A}

\section{Radiosonde Station Network}

Huntington, WV (HTS)

Salem, IL (SLO)

Centerville, AL (CKL)

Lake Charles, LA (LCH)

Jackson, MS (JAN)

Monett, MO (UMN)

Longview, TX (GGG)

Apalachicola, FL (AQQ)

Tampa, FL (TPA)

West Palm Beach, FL (PBI)

Key West, FL (EYW)

Boothville, LA (BVE)

Victoria, TX (VCT)

Brownsville, TX (BRO)

Greensboro, NC (GSO)

Dayton, OH (DAY)

Waycross, GA (AYS)

Athens, GA (AHN)

Charleston, SC (CHS)

Nashville, TN (BNA)

Stephenville, TX (SEP)

Little Rock, AR (LIT) 


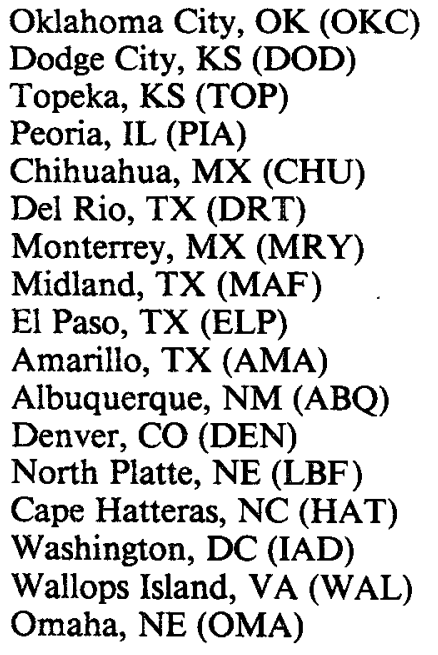

APPENDIX B

\section{Local Climatological Stations}

\begin{tabular}{|c|c|c|c|}
\hline Station & Latitude & Longitude & $\begin{array}{c}\text { Elevation } \\
(\mathrm{m})\end{array}$ \\
\hline $\begin{array}{c}\text { Dallas-Ft. Worth, } \\
\text { TX (DFW) }\end{array}$ & $32^{\circ} 54 \mathrm{~N}$ & $97^{\circ} 02^{\prime} \mathrm{W}$ & 165 \\
\hline Wichita, KS (ICT) & $37^{\circ} 39 \mathrm{~N}$ & $97^{\circ} 25^{\prime} \mathrm{W}$ & 396 \\
\hline Tulsa, OK (TUL) & $36^{\circ} 12 \mathrm{~N}$ & $95^{\circ} 54^{\prime} \mathrm{W}$ & 195 \\
\hline $\begin{array}{l}\text { Jackson, MS } \\
\text { (JAN) }\end{array}$ & $32^{\circ} 19 \mathrm{~N}$ & $90^{\circ} 05^{\prime} \mathrm{W}$ & 87 \\
\hline $\begin{array}{l}\text { Shreveport, LA } \\
\text { (SHV) }\end{array}$ & $32^{\circ} 28 \mathrm{~N}$ & $93^{\circ} 49^{\prime} \mathrm{W}$ & 76 \\
\hline $\begin{array}{l}\text { Columbia, MO } \\
\text { (COU) }\end{array}$ & $38^{\circ} 49^{\prime} \mathrm{N}$ & $92^{\circ} 13^{\prime} \mathrm{W}$ & 266 \\
\hline $\begin{array}{l}\text { Atlanta, GA } \\
\text { (ATL) }\end{array}$ & $33^{\circ} 39^{\prime} \mathrm{N}$ & $84^{\circ} 25^{\prime} \mathrm{W}$ & 303 \\
\hline $\begin{array}{l}\text { Montegomery, AL } \\
\text { (MGM) }\end{array}$ & $32^{\circ} 18^{\prime} \mathrm{N}$ & $86^{\circ} 24^{\prime} \mathrm{W}$ & 58 \\
\hline $\begin{array}{l}\text { Little Rock, AR } \\
\text { (LIT) }\end{array}$ & $34^{\circ} 44^{\prime} \mathrm{N}$ & $92^{\circ} 14^{\prime} \mathrm{W}$ & 77 \\
\hline
\end{tabular}

\section{REFERENCES}

Anthes, R. A., and Y. H. Kuo, 1986: The influence of soil moisture on circulations over North America on short time scales. Namias Symposium, J. O. Roads, Ed., Scripps Institute of Oceanography, Ref. Ser. 86-17, 132-147.

Bellamy, J. C., 1949: Objective calculation of divergence, vertical velocity and vorticity. Bull. Amer. Meteor. Soc., 30, 45-49.

Blackadar, A. K., 1957: Boundary layer wind maxima and their significance for the growth of nocturnal inversions. Bull. Amer. Meteor. Soc., 38, 283-290.

Blake, D. W., T. N. Krishnamurti and S. V. Low-Nam, 1983: Heat low over the Saudi Arabian desert during May 1979 (Summer MONEX). Mon. Wea. Rev., 111, 1759-1775.

Bonner, W. D., 1968: Climatology of the low-level jet. Mon. Wea. Rev., 96, 833-850.

Bosart, L. F., and F. Sanders, 1981: The Johnstown flood of July 1977: A long-lived convective system. J. Atmos. Sci., 38, 16161642.

Bouchet, R. J., 1963: Evapotranspiration reelle et potentielle, signi- fication climatique. Int. Assoc. Sci. Hydrol., Publ. No. 62, 134142.

Brutsaert, W., 1982: Evaporation into the Atmosphere. Reidel, 209262.

- , and H. Stricker, 1979: An advection-aridity approach to estimate actual regional evapotranspiration. Water Resour. Res., $15,443-449$.

Charney, J. G., 1975: Dynamics of deserts and drought in the Sahel. Quart. J. Roy. Meteor. Soc., 101, 193-202.

,- 1976 : Reply to "Comment on the paper 'Dynamics of deserts and drought in the Sahel' by J. G. Charney". Quart. J. Roy. Meteor. Soc., 102, 468.

- , P. H. Stone and W. J. Quirk, 1975: Drought in the Sahara: A biogeophysical feedback mechanism. Science, 187, 434-435.

,-- and -1976 : Drought in the Sahara: Insufficient biogeophysical feedback? Reply. Science, 191, 100-102.

-, W. J. Quirk, S.-H. Chow and J. Kornfield, 1977: A comparative study of the effects of albedo change on drought in semi-arid regions. J. Atmos. Sci., 34, 1366-1385.

Cline, A. K., 1974: Scalar- and planar-valued curve fitting using splines under tension. Commun. Assoc. Comput. Machinery, 17, 218223.

Dickson, R. R., 1980: Weather and circulation of June 1980-Inception of a heat wave and drought over the central and southern Great Plains. Mon. Wea. Rev., 100, 1469-1474.

Gutman, G., 1984: Numerical experiments on land surface alterations with a zonal model allowing for interaction between the geobotanic state and climate. J. Atmos. Sci., 41, 2679-2685.

Holton, J. R., 1967: The diurnal boundary layer wind oscillation above sloping terrain. Tellus, 19, 199-205.

Howell, T. A., C. J. Phene and D. W. Meek, 1983: Evaporation from screened Class A pans in a semi-arid climate. Agric. Meteor., 29, 111-124.

Kalkstein, L. S., and K. M. Valimont, 1986: An evaluation of summer discomfort in the United States using a relative climatological index. Bull. Amer. Meteor. Soc., 67, 842-848.

Karl, T. R., and R. G. Quayle, 1981: The 1980 summer heat wave and drought in historical perspective. Mon. Wea. Rev., 109, 2055-2073.

Livezey, R. E., 1980: Weather and circulation of July 1980-Climax of an historic heat wave and drought over the United States. Mon. Wea. Rev., 108, 1708-1716.

Maddox, R. A., D. M. Rodgers, W. Deitrich and D. L. Bartels, 1981: Meteorological settings associated with significant convective storms in Colorado. NOAA Tech. Memo. ERL OWRM-4. [Available from NOAA Environmental Research Laboratories, 325 Broadway, Boulder, CO 80303.]

Mintz, Y., and J. Shukla, 1982: Influence of land-surface evapotranspiration on the earth's climate. Science, 215, 1498-1501.

Monteith, J. L., 1981: Evaporation and surface temperature. Quart. J. Roy. Meteor. Soc., 102, 1-27.

Namias, J., 1962: Influence of abnormal heat sources and sinks on atmospheric behavior. Proc. Int. Symp. on Numerical Weather Prediction, Tokyo, 1960, Meteor. Soc. Japan, 615-627.

- 1982: Anatomy of Great Plains protracted heat waves (especially the 1980 U.S. summer drought). Mon. Wea. Rev., 110, 824838.

- 1983: Some causes of United States drought. J. Climate Appl. Meteor., 22, 30-39.

O'Brien, J. J., 1970: Alternative solution to the classical vertical velocity problem. J. Atmos. Sci., 9, 197-203.

Ooyama, K., 1969: Numerical simulation of the life cycle of tropical cyclones. J. Atmos. Sci., 26, 3-40.

Pedder, M. A., 1981: On the errors of kinematic vertical motion estimation using divergence bias adjustment procedures. Mon. Wea. Rev., 109, 1813-1816.

Penman, H. L., 1956: Estimating evaporation. Trans. Amer. Geophys. Union., 31, 43-50.

Priestly, C. H. B., and R. J. Taylor, 1972: On the assessment of 
surface heat flux and evaporation using large-scale parameters. Mon. Wea. Rev., 100, 81-92.

Purvis, J. C., 1961: Graphical solution of the Penman equation for potential evapotranspiration. Mon. Wea. Rev., 89, 192-196.

Rasmusson, E. M., 1968: Atmospheric water vapor transport and the water balance of North America. Part II: Large-scale water balance investigations. Mon. Wea. Rev., 96, 720-734.

Reiter, E. R., and M. Tang, 1984: Plateau effects on diurnal circulation patterns. Mon. Wea. Rev., 112, 638-651.

Rowntree, P. R., and J. A. Bolton, 1983: Simulation of the atmospheric response to soil moisture anomalies over Europe. Quart. J. Roy. Meteor. Soc., 109, 501-526.

Smith, E., 1986a: The structure of the Arabian Heat Low. Part I: Surface energy budget. Mon. Wea. Rev., 114, 1067-1083.

_ 1986b: The structure of Arabian Heat Low. Part II: Bulk tropospheric heat budget and implications. Mon. Wea. Rev., 114, 1084-1102.

Twomey, S., and P. Squires, 1959: The influence of cloud nucleus population on the microstructure and stability of convective clouds. Tellus, 11, 408-411.

Uccellini, L. W., 1980: On the role of upper tropospheric jet streaks and leeside cyclogenesis in the development of low-level jets in the Great Plains. Mon. Wea. Rev., 108, 1689-1696.

Wagner, A. J., 1980: Weather and circulation of August 1980-Eastward spread of heat wave and drought. Mon. Wea. Rev., 108, 1924-1932.

Wallace, J. M., 1975: Diurnal variation in precipitation and thunderstorm frequency over the conterminous United States. Mon. Wea. Rev., 103, 406-419.

Walsh, J. E., 1986: Surface-atmosphere interactions over the continents: The Namias influence. Namias Symposium, J. O. Roads, Ed., Scripps Institute of Oceanography, Ref. Ser. 86-17, 132147.

Yeh, T.-C., R. T. Wetherald and S. Manabe, 1984: The effect of soil moisture on the short-term climate and hydrology change-A numerical experiment. Mon. Wea. Rev., 112, 474-490. 